\title{
Contributions of an Endonuclease IV Homologue to DNA Repair in the African Swine Fever Virus ${ }^{\dagger}$
}

\author{
Brandon J. Lamarche ${ }^{\ddagger}$ and Ming-Daw Tsai*,§ \\ Departments of Chemistry and Biochemistry, The Biophysics Program, and The Ohio State Biochemistry Program, The Ohio \\ State University, Columbus, Ohio 43210
}

Received September 2, 2005; Revised Manuscript Received December 27, 2005

\begin{abstract}
We recently demonstrated that African swine fever virus DNA polymerase $\mathrm{X}$ (Pol $\mathrm{X}$ ) is extremely error-prone during single-nucleotide gap-filling and that the downstream ASFV DNA ligase seals 3 ' mismatched nicks with high efficiency. To further assess the credence of our hypothesis that these proteins may promote viral diversification by functioning within the context of an aberrant DNA repair pathway, herein we characterize the third protein expected to function in this system, a putative AP endonuclease (APE). Assays of the purified protein using oligonucleotide substrates unequivocally establish canonical APE activity, 3'-phosphatase and 3'-phosphodiesterase activities (in the context of a singlenucleotide gap), $3^{\prime} \rightarrow 5^{\prime}$ exonuclease activity (in the context of a nick), and nucleotide incision repair activity against 5,6-dihydrothymine. The $3^{\prime} \rightarrow 5^{\prime}$ exonuclease activity is shown to be highly dependent upon the identity of the nascent $3^{\prime}$ base pair and to be inhibited when 2-deoxyribose-5-phosphate, rather than phosphate, constitutes the $5^{\prime}$ moiety of the nick. ASFV APE retains activity when assayed in the presence of EDTA but is inactivated by incubation with 1,10-phenanthroline in the absence of a substrate, suggesting that it is an endonuclease IV homologue possessing intrinsic metal cofactors. The activities of ASFV APE, when considered alongside those of Pol X and ASFV DNA ligase, provide an enhanced understanding of (i) the types of damage that are likely to be sustained by the viral genome and (ii) the mechanisms by which the minimalist ASFV DNA repair pathway, consisting of just these three proteins, contributes to the fitness of the virus.
\end{abstract}

Apurinic/apyrimidinic (AP) ${ }^{1}$ sites, generated either by DNA glycosylase-mediated or spontaneous base loss, can be both mutagenic $(1,2)$ and cytotoxic $(3)$ and are among the most abundant types of damage found in DNA (4). Although they can be processed by AP lyases, which cleave $3^{\prime}$ to the lesion by a $\beta$-elimination mechanism to generate a single-nucleotide gap flanked by $5^{\prime}$-phosphate and a $3^{\prime}$ polymerase-blocking $\alpha, \beta$-unsaturated aldehyde (5-7), AP sites are likely to be processed predominantly by AP endonucleases (8), which catalyze hydrolysis of the sugarphosphate backbone $5^{\prime}$ of the lesion to generate a singlenucleotide gap flanked by a polymerase-usable 3 '-hydroxyl

$\doteqdot$ This work was supported by NIH Grant GM43268. B.J.L. was supported in part by a predoctoral NIH CBIP fellowship (2T32 GM08512).

* To whom correspondence should be addressed: Department of Chemistry, The Ohio State University, Columbus, Ohio 43210. Telephone: (614) 292-3080. Fax: (614) 292-1532. E-mail: tsai@chemistry.ohio-state.edu.

Department of Chemistry only.

$\S$ A member of the Genomics Research Center, Academia Sinica, Taiwan.

${ }^{1}$ Abbreviations: AP, apurinic/apyrimidinic (abasic); APE, AP endonuclease; 5'-dRP, 5'-2-deoxyribose-5-phosphate; NIR, nucleotide incision repair; FEN1, flap endonuclease 1; ASFV, African swine fever virus; Pol, DNA polymerase; MMS, methyl methanesulfonate; AEBSF, 4-(2-aminoethyl)-benzenesulfonyl fluoride; PMSF, phenylmethylsulfonyl fluoride; BSA, bovine serum albumin; PNK, polynucleotide kinase; THF, tetrahydrofuran; DHT, 5,6-dihydrothymine; UDG, uracil DNA glycosylase; DTT, dithiothreitol; NP-40, (octylphenoxy)polyethoxyethanol; $5^{\prime}-\mathrm{P}_{\mathrm{i}}$-THF, the tetrahydrofuran analogue of $5^{\prime}$-dRP. and 5'-2-deoxyribose-5-phosphate (5'-dRP) (7). Two families of APEs have been identified to date; these consist of proteins with homology to Escherichia coli exonuclease III $^{2}$ and proteins with homology to $E$. coli endonuclease IV. While the reaction that these proteins catalyze is identical, they differ dramatically in both tertiary structure and mechanisms of catalysis (9). Whereas exonuclease III displays a fourlayered $\alpha, \beta$-sandwich fold and employs a single readily dissociatable magnesium ion $(9,10)$, endonuclease IV is an $\alpha_{8} \beta_{8}$ TIM barrel that utilizes three tightly bound zinc ions $(9,11)$.

In addition to their APE activities, both exonuclease III and endonuclease IV (and their respective homologues) possess an array of $3^{\prime}$ processing activities (within the general categories of 3'-phosphatase and 3'-phosphodiesterase) responsible for removing phosphate and ribose fragments, produced both by oxidative damage and the AP lyase activity described above, to generate polymerase-usable 3 '-hydroxyl termini $(7,12-15)$. APEs from both families are also capable of acting as $3^{\prime} \rightarrow 5^{\prime}$ exonucleases at nicks $(16,17)$; because this activity is most efficient for nicks containing a $3^{\prime}$ mismatched base pair, it is speculated to enhance the fidelity of DNA repair by providing, in trans, the proofreading activity that is typically absent in repair polymerases (16). Most recently, APEs from both protein families have been

\footnotetext{
${ }^{2}$ This apparent misnomer is rooted in the fact that the $3^{\prime} \rightarrow 5^{\prime}$ exonuclease activity of this enzyme was discovered before its AP endonuclease activity.
} 
shown to catalyze nucleotide incision repair (NIR) in which, bypassing the step of base removal by a DNA glycosylase, the APE directly incises the sugar-phosphate backbone 5' to a nucleotide containing a damaged base ${ }^{3}$ to generate a single-nucleotide gap flanked by a $3^{\prime}$-hydroxyl and a $5^{\prime}$ "dangling nucleotide" - which can subsequently be removed by a flap endonuclease 1 (FEN1)-like activity (18-21). Owing to their repertoire of critical DNA repair activities, it is not surprising that APEs are conserved in all three kingdoms of life, in addition to being found in a number of viral genomes $(22,23)$.

The African swine fever virus (ASFV) is a large doublestranded DNA virus that principally targets macrophage cells in domestic pigs $(24-26)$. It displays a phase of cytoplasmic DNA synthesis $(27,28)$ and accordingly encodes its own replicative DNA polymerase (23) and a relatively simple DNA repair system consisting of a polymerase (Pol X) and an ATP-dependent DNA ligase, both of which have been characterized (29-34), in addition to a putative APE (23, $35)$.

Our previous findings that Pol $\mathrm{X}$ displays low fidelity during single-nucleotide gap-filling (30) and that the ASFV DNA ligase efficiently seals nicks containing $3^{\prime}$ mismatched base pairs (potential products of Pol X catalysis) $(31,34)$ have led us to hypothesize a correlation between these errorprone/error-tolerant enzymatic activities and the diversity known to exist among ASFV isolates. Specifically, we have suggested that ASFV sequence diversity, corresponding to small insertions/deletions or base substitutions (36), might be, in part, the consequence of an aberrant DNA repair pathway in which chemically damaged nucleotides are replaced with undamaged, although incorrect, nucleotides $(30,31,34)$. However, for the error-proneness of Pol X and the error-tolerance of ASFV DNA ligase to be biologically relevant, they would need to function within the context of a complete DNA repair system in which the other components are capable of tolerating mismatched repair intermediates and products. The work described herein was undertaken as part of an ongoing effort to answer the following questions: (i) Is a complete DNA repair system, including ASFV-encoded and host-derived activities, available for converting damaged sites in the ASFV genome into a contiguous duplex product? (ii) If such a system exists, are each of the components of this system able to tolerate and/ or utilize mismatched repair intermediates and mismatched duplex products?

In light of the diverse APE activities described above, it seemed likely that the putative ASFV APE would be an integral component in the ASFV DNA repair pathway and, moreover, that it might influence the overall fidelity (i.e., error-proneness) of the pathway. Although phylogenetic analyses suggest that ASFV gene E296R encodes an APE $(23,35)$, the nuances of enzymatic catalysis, particularly for a multifunctional enzyme (as APEs tend to be), are only accurately understood via empirical analysis of the protein. The specific questions guiding the work reported here were as follows: Is the product of ASFV gene E296R a functional homologue of exonuclease III or of endonuclease IV? What activities are present in this protein? Does this protein

\footnotetext{
${ }^{3}$ NIR substrates include ring-saturated pyrimidines such as 5,6dihydrothymine, ring-fragmented purines, and $\alpha$-anomeric nucleotides.
}

influence the overall fidelity of the ASFV DNA repair pathway? On the basis of this protein's activities, what can we surmise to be the most likely types of damage sustained by the viral genome?

\section{EXPERIMENTAL PROCEDURES}

E. coli Strains, ASFV Clones, and Materials. BW528 cells (nfo-1::kan, $\Delta$ (xthA-pncA)90) (37) were provided by B. Weiss (Department of Pathology, Emory University, Atlanta, GA). ASFV BASE and BASH (two separate clones containing genomic fragments from ASFV isolate BA71V) were provided by L. Dixon (Institute for Animal Health, Pirbright Laboratory, U.K.). The pET21b expression plasmid was from Novagen. Methyl methanesulfonate (MMS, 99\%), tert-butyl hydroperoxide (70 wt \% in water), 1,7-phenanthroline, and 1,10-phenanthroline were from Aldrich. 4-(2-Aminoethyl)benzenesulfonyl fluoride (AEBSF) was from BioShop. Phenylmethylsulfonyl fluoride (PMSF), egg white lysozyme, Tween 20, and Triton X-100 were from Sigma. Complete, EDTA-free Protease Inhibitor Cocktail Tablets, bovine serum albumin (BSA), and 3'-phosphatase-free polynucleotide kinase (PNK) were from Roche. Sep-Pak C18 columns were from Waters. Standard oligonucleotides, including those containing the tetrahydrofuran (THF) abasic site analogue (which lacks the $\mathrm{C} 1^{\prime}$ hydroxyl of ribose and therefore is not prone to $\beta$-elimination), were from Integrated DNA Technologies. The 5,6-dihydrothymine (DHT)-containing oligonucleotide used for the NIR assay was from Synthegen. $\left[\gamma^{32} \mathrm{P}\right]$ ATP was from MP Biomedicals. T4 PNK, uracil DNA glycosylase (UDG), UDG inhibitor, and endonuclease III were from New England Biolabs. Microspin G-25 columns were from Amersham Biosciences. Talon cobalt resin was from Clonetech. NP-40 was from USB. Hydroxyapatite was from BioRad, and P-11 was from Whatman. Amicon Ultra centrifugal filter devices were from Millipore. Slide-A-Lyzer dialysis cassettes and GelCode Blue were from Pierce. Yeast tRNA was from Ambion. $\mathrm{MgCl}_{2}$ and $\mathrm{MnCl}_{2}$ were $1 \mathrm{M}$ standard solutions from Sigma. All other metal solutions were prepared from their respective chloride salts, except nickel and copper, which were prepared from their sulfate salts. $E$. coli endonuclease IV was from Trevigen and was used without further purification; its concentration was determined by UV absorbance with correction to account for the BSA present in the storage buffer that it is supplied in. Materials and reagents not listed here were of standard molecular biology grade.

Sequence Alignment and Unrooted Phylogenetic Tree Construction. The protein product of ASFV gene E296R (from the BA71V isolate; NCBI accession number 2113434ET), E. coli endonuclease IV (AAA60529), and its homologue Saccharomyces cerevisiae Apn1 (P22936), as well as E. coli exonuclease III (AAC74819) and its homologues Homo sapiens Ape1 (CAA46925), H. sapiens Ape2 (NP_055296), S. cerevisiae Apn2 (NP_009534), and Schizosaccharomyces pombe Apn2 (P87175), were aligned and subsequently plotted as an unrooted dendrogram using the default settings of the online ClustalW program (http:// clustalw.genome.jp/) (38).

Alignment of the putative ASFV APE with endonuclease IV and Apn1 was performed as described above. The zinccoordinating residues of endonuclease IV are indicated on 
the basis of the crystal structures (PDB accession numbers 1QTM and 1QUM) reported by Tainer and co-workers (11).

Preparation of E. coli Strain BL100. To eliminate background APE activity in the survival assays described below and to prevent contamination of purified ASFV APE by the endogenous $E$. coli AP endonucleases [exonuclease III $(x t h)$ and endonuclease IV $(n f o)$ ], the double knockout strain BW528 (nfo-1::kan, $\Delta(x t h A-p n c A) 90)$ (37) was selected as an appropriate genetic background. To maximize expression of ASFV APE in BW528 cells, they were endowed with an IPTG-inducible chromosomal copy of the T7 RNA polymerase using Novagen's $\lambda$ DE3 Lysogenization Kit. Because ASFV gene E296R contains a number of codons used infrequently in $E$. coli, the BW528(DE3) cells prepared above were transformed with Novagen's pLysSRARE $\left(\mathrm{Cm}^{\mathrm{R}}\right)$ plasmid; this plasmid is not commercially available and was therefore isolated directly from Rosetta(DE3)pLysS cells. The resulting cells, BW528(DE3)pLysSRARE, will be referred to simply as BL100.

Cloning. ASFV gene E296R was amplified from a mixture of BASE and BASH (two separate clones containing genomic fragments from ASFV isolate BA71V) and ligated into the NdeI and $X h o I$ sites of pET21b $\left(\mathrm{Ap}^{\mathrm{R}}\right)$. This plasmid, designated pET21-ASFV APE, codes for the full-length protein containing an unmodified $\mathrm{N}$ terminus and a $\mathrm{C}$ terminal $\mathrm{His}_{6}$ tag.

Survival Assays. BL100 cells, with or without the pET21ASFV APE plasmid, were grown overnight at $37^{\circ} \mathrm{C}$ in LB medium containing $50 \mu \mathrm{g} / \mathrm{mL}$ kanamycin and $34 \mu \mathrm{g} / \mathrm{mL}$ chloramphenicol; $100 \mu \mathrm{g} / \mathrm{mL}$ ampicillin was also included for cells containing the pET21-ASFV APE plasmid. A total of $1 \mathrm{~mL}$ of saturated overnight culture was back-diluted into $25 \mathrm{~mL}$ of fresh medium and grown in an analogous manner to an $\mathrm{OD}_{600}$ of $0.5-0.6$ before inducing protein expression with $1 \mathrm{mM}$ IPTG for $2 \mathrm{~h}$; cells lacking pET21-ASFV APE were subjected to identical treatment as cells containing the expression plasmid. Cultures were then placed on ice for 15 min and subsequently diluted serially with iced LB containing $1 \mathrm{mM}$ IPTG. A total of $175 \mu \mathrm{L}$ of diluted cell suspension was added to $3.3 \mathrm{~mL}$ of $46{ }^{\circ} \mathrm{C}$ molten top agarose (LB supplemented with $0.65 \%$ agarose) followed by either MMS or tert-butyl hydroperoxide to achieve the indicated concentration; parallel assays were performed with water in place of the DNA-damaging agent. After rapid yet gentle mixing, the top agarose mixture was poured onto LB plates (prewarmed to $37^{\circ} \mathrm{C}$ ) containing $1 \mathrm{mM}$ IPTG and the appropriate antibiotics. Plates were incubated at $37^{\circ} \mathrm{C}$ until the maximal number of colonies had formed (typically between 48 and $60 \mathrm{~h}$ ). Percent survival was calculated as (the number of colonies per plate in the presence of DNA-damaging agent/ the number of colonies per plate in the absence of DNAdamaging agent) $\times 100$. Four different dilutions of cell suspension were plated for each drug concentration; the reported percent survival represents an average from these different plates. The entire survival assays were performed multiple times. While the absolute values of percent survival fluctuated some from one independent experiment to the next, the trends were consistently reproducible.

Preparation of Cell-Free Extracts. BL100 cells, both with and without the pET21-ASFV APE expression plasmid, were grown and induced exactly as described above for the survival assays. Immediately after the $2 \mathrm{~h}$ induction period, cultures were placed on ice for $15 \mathrm{~min}$ and $\mathrm{OD}_{600}$ was measured; values were typically between 1.2 and 1.3. Assuming that $1 \mathrm{OD}_{600}=2.5 \times 10^{8}$ cells $/ \mathrm{mL}$, a volume of culture corresponding to $1.6 \times 10^{9}$ cells (typically $\geq 5 \mathrm{~mL}$ ) was pelleted at $4{ }^{\circ} \mathrm{C}$ and $10000 \mathrm{~g}$ for $10 \mathrm{~min}$. After careful aspiration of the supernatant, cell pellets were flash-frozen in liquid nitrogen and stored at $-20{ }^{\circ} \mathrm{C}$ for later use.

Frozen cell pellets were thawed and then lysed at room temperature by gentle resuspension in $800 \mu \mathrm{L}$ of Novagen's primary amine-free Bug Buster reagent, which had been supplemented with $1 \mathrm{mM}$ DTT, $100 \mu \mathrm{M}$ AEBSF, and Roche's Complete, EDTA-free Protease Inhibitor Cocktail (inhibitor solution was prepared by dissolving 1 tablet in 1 $\mathrm{mL}$ of water; added $1 \mu \mathrm{L}$ of inhibitor solution $/ \mathrm{mL}$ of Bug Buster reagent). After cells were thoroughly resuspended, lysis was allowed to continue for an additional $10 \mathrm{~min}$ at room temperature with gentle rocking. Cellular debris was then pelleted at $4{ }^{\circ} \mathrm{C}$ and $16000 \mathrm{~g}$ for $20 \mathrm{~min}$. The supernatant was removed to a clean tube, mixed thoroughly, and then aliquoted and flash-frozen in liquid nitrogen prior to storage at $-80{ }^{\circ} \mathrm{C}$. When cell-free extract was to be supplemented with exogenous metal ions, it was prepared with $1 \mathrm{mM}$ $\beta$-mercaptoethanol instead of DTT.

Preparation of DNA Substrates. Oligonucleotides were purified by denaturing polyacrylamide gel electrophoresis under standard conditions. After gel extraction, oligonucleotides were desalted on Sep-Pak C18 columns, dried in a speed-vac, and resuspended in TE buffer $(10 \mathrm{mM}$ Tris- $\mathrm{HCl}$ and $1 \mathrm{mM}$ EDTA at $\mathrm{pH}$ 7.5). Concentrations were determined by UV absorbance at $260 \mathrm{~nm}$ using extinction coefficients calculated by the oligo analyzer tool on Integrated DNA Technology's website.

The appropriate oligonucleotides were 5 '-end-labeled using T4 PNK and $\left[\gamma^{3}{ }^{32} \mathrm{P}\right]$ ATP. A $3^{\prime}$-phosphatase-deficient mutant of PNK was used to $5^{\prime}$-end-label the 3'-phosphorylated 25mer; in our hands, although the $3^{\prime}$-phosphatase activity of this mutant is indeed reduced relative to WT, it is not abolished; when using a 100-fold dilution of the protein and an oligonucleotide concentration of $1 \mu \mathrm{M}$, a 4 min incubation was found to provide sufficient $5^{\prime}$ phosphorylation while minimizing 3' dephosphorylation. After heat inactivation of PNK, free ATP was removed on a Microspin G-25 column. Substrates were assembled by combining the component oligonucleotides at room temperature; heating and slow cooling the mixture to effect complete annealing was found to be unnecessary. For substrates assembled from two oligonucleotides (A:THF, A:U, and A:DHT; see Figure 1), the templating oligonucleotide (lacking the lesion) was added in 5\% molar excess. Substrates consisting of three oligonucleotides (see Figure 1) were assembled with the template in $5 \%$ molar excess over the upstream oligonucleotide and the downstream oligonuclotide in 5\% molar excess over the template. On average, only $2 \%$ of the substrate molecules were labeled. Prior to storage at $4{ }^{\circ} \mathrm{C}$, substrates were diluted to a concentration of $6 \mu \mathrm{M}$ using the following buffer: 50 $\mathrm{mM}$ HEPES, $100 \mathrm{mM} \mathrm{KCl}, 15 \%$ glycerol $(\mathrm{v} / \mathrm{v}), \mathrm{pH} \rightarrow 7.8$ with $\mathrm{KOH}$ while at $37^{\circ} \mathrm{C}$.

Assay to Probe for Induction of APE Activity. Cell-free extracts prepared from BL100 cells either containing or lacking the pET21-ASFV APE plasmid were diluted 20-fold into buffer consisting of $50 \mathrm{mM}$ HEPES, $100 \mathrm{mM} \mathrm{KCl}, 15 \%$ glycerol (v/v), $\mathrm{pH} \rightarrow 7.8$ with $\mathrm{KOH}$ while at $37{ }^{\circ} \mathrm{C}$, 


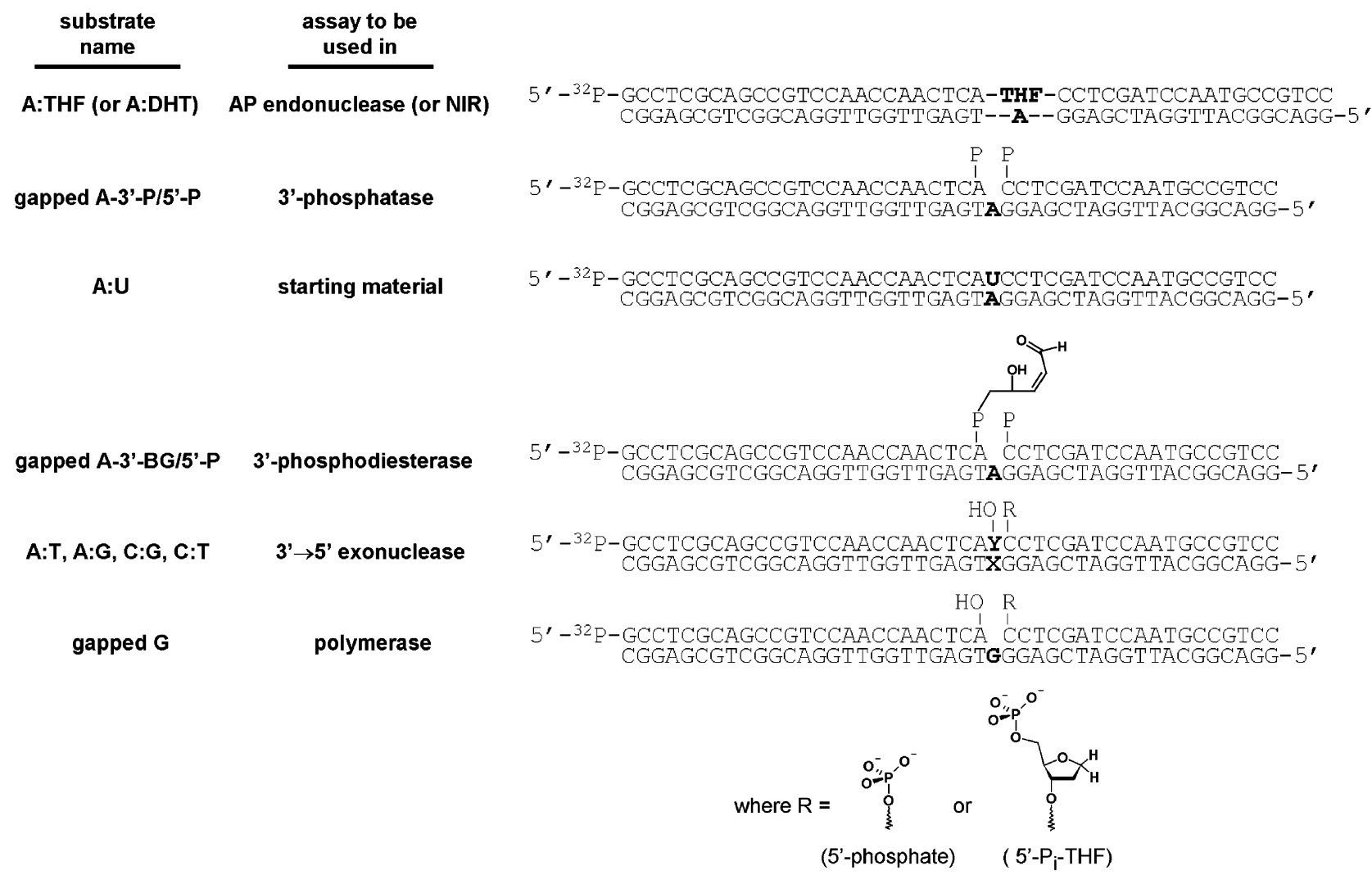

FIGURE 1: DNA substrates. Substrates are named according to the base pair of interest, with the undamaged nucleotide in the contiguous, templating strand being listed first and the nucleotide subject to enzymatic processing being listed second. Accordingly, the four nicked substrates used in the $3^{\prime} \rightarrow 5^{\prime}$ exonuclease assays are identified as $\mathrm{X}: \mathrm{Y}$, where $\mathrm{X}$ denotes the templating nucleotide and $\mathrm{Y}$ represents the nucleotide that would have been incorporated by a polymerase during single-nucleotide gap-filling. THF is the tetrahydrofuran analogue of an abasic site. The substrate used for the NIR assay was similar to the A:THF substrate shown here, except that THF was replaced with DHT. Wherever a strand break exists, the $3^{\prime}$ and $5^{\prime}$ moieties of the nick or gap are highlighted: while P is used to denote either a $3^{\prime}-$ or $5^{\prime}$-phosphate, $\mathrm{OH}$ represents a 3'-hydroxyl; R denotes either 5'-phosphate or 5'- $\mathrm{P}_{\mathrm{i}}$-THF (the THF analogue of 5'-2-deoxyribose-5-phosphate); the $3^{\prime}$-polymerase-blocking group 4-hydroxy-2-pentenal-5-phosphate (whose structure is shown) has simply been abbreviated as BG (for "blocking group").

supplemented with $3 \mathrm{mg} / \mathrm{mL}$ BSA and $600 \mu \mathrm{M}$ DTT. The $\mathrm{A}:$ THF substrate was prepared as an $800 \mathrm{nM}$ solution in the same buffer but contained $1 \mathrm{mM}$ EDTA and lacked both BSA and DTT. After both the protein and the DNA solutions were preincubated at $37{ }^{\circ} \mathrm{C}$ for $5 \mathrm{~min}, 20 \mu \mathrm{L}$ of protein solution was added to $20 \mu \mathrm{L}$ of DNA solution. After $90 \mathrm{~min}$ at $37{ }^{\circ} \mathrm{C}$, the reaction was quenched by the addition of formamide to a final concentration of $50 \%$. Reaction products were resolved on $15 \%$ denaturing polyacrylamide gels and visualized by phosphor screen autoradiography using a STORM840 scanner from Molecular Dynamics. Band intensity quantitation and data plotting were with ImageQuant and SigmaPlot, respectively.

Phenanthroline Inactivation of the Induced ASFV APE Activity. Cell-free extract prepared from BL100 cells containing the pET21-ASFV APE plasmid was diluted 5-fold into buffer consisting of $50 \mathrm{mM}$ HEPES, $100 \mathrm{mM} \mathrm{KCl}, 15 \%$ glycerol (v/v), $\mathrm{pH} \rightarrow 7.8$ with $\mathrm{KOH}$ while at $37{ }^{\circ} \mathrm{C}, 3 \mathrm{mg} /$ $\mathrm{mL}$ BSA, and $600 \mu \mathrm{M}$ DTT. This solution was supplemented with either water, $600 \mu \mathrm{M}$ 1,7-phenanthroline (a nonchelating isomer), or $600 \mu \mathrm{M} \mathrm{1,10-phenanthroline} \mathrm{(the} \mathrm{metal-chelating}$ isomer) prior to incubation at $50{ }^{\circ} \mathrm{C}$ for times ranging from 0 to $12 \mathrm{~min}$. Samples were removed from $50{ }^{\circ} \mathrm{C}$ directly to an ice bath, followed by centrifugation for $1 \mathrm{~min}$ to pool the moisture that had condensed on tube lids. The A:THF substrate was prepared as an $800 \mathrm{nM}$ solution in the same buffer but contained $1 \mathrm{mM}$ EDTA and lacked both BSA and
DTT. After both the protein and the DNA solutions were preincubated at $37{ }^{\circ} \mathrm{C}$ for $5 \mathrm{~min}, 20 \mu \mathrm{L}$ of protein solution was added to $20 \mu \mathrm{L}$ of DNA solution. After $20 \mathrm{~s}$, the reaction was quenched and the products were analyzed as described above. Percent activity was plotted as (the concentration of product for the reaction of interest/the concentration of product for the reaction that was not preincubated at $50{ }^{\circ} \mathrm{C}$ and did not contain a phenanthroline isomer) $\times 100$.

Affect of Exogenous Metal Ions on the Induced ASFV APE Activity. The cell-free extract (containing $1 \mathrm{mM} \beta$-mercaptoethanol rather than DTT) prepared from BL100 cells containing the pET21-ASFV APE plasmid was diluted 30fold into a buffer consisting of $50 \mathrm{mM}$ HEPES, $100 \mathrm{mM}$ $\mathrm{KCl}, 15 \%$ glycerol (v/v), $\mathrm{pH} \rightarrow 7.8$ with $\mathrm{KOH}$ while at 37 ${ }^{\circ} \mathrm{C}, 1.5 \mathrm{mg} / \mathrm{mL} \mathrm{BSA}$, and $167 \mu \mathrm{M} \beta$-mercaptoethanol. This solution was supplemented with either water or a divalent metal ion at a concentration of $2 \mathrm{mM}$. The A:THF substrate was prepared as an $800 \mathrm{nM}$ solution in the same buffer but lacked BSA, $\beta$-mercaptoethanol, and metal ion. After both the protein and the DNA solutions were preincubated at 37 ${ }^{\circ} \mathrm{C}$ for $5 \mathrm{~min}, 20 \mu \mathrm{L}$ of protein solution was added to $20 \mu \mathrm{L}$ of DNA solution. After $20 \mathrm{~s}$, reactions were quenched and the products were analyzed as described above.

Protein Expression and Purification. In LB medium supplemented with $50 \mu \mathrm{g} / \mathrm{mL}$ kanamycin, $34 \mu \mathrm{g} / \mathrm{mL}$ chloramphenicol, and $100 \mu \mathrm{g} / \mathrm{mL}$ ampicillin, BL100 cells containing pET21-ASFV APE were grown at $37{ }^{\circ} \mathrm{C}$ to mid-log phase 
and then induced with $1 \mathrm{mM}$ IPTG at $30^{\circ} \mathrm{C}$ for $10 \mathrm{~h}$. Cells were pelleted at $4{ }^{\circ} \mathrm{C}$ and immediately subjected to the lysis and purification protocol described below.

All purification steps were conducted at $4{ }^{\circ} \mathrm{C}$, unless noted otherwise. Buffers used for the cobalt column were as follows. Buffer A: $50 \mathrm{mM} \mathrm{NaH} \mathrm{PO}_{4}, 300 \mathrm{mM} \mathrm{NaCl}, 10 \%$ glycerol (v/v), pH 8.0, $5 \mathrm{mM}$ imidazole, and $1 \mathrm{mM}$ $\beta$-mercaptoethanol. Buffer B: the same as buffer $\mathrm{A}$ but supplemented with $1 \%$ NP-40. Buffer C: the same as buffer $\mathrm{B}$ but with $\mathrm{pH} 7.0$ and $10 \mathrm{mM}$ imidazole. Buffer D: the same as buffer $\mathrm{C}$ but with $1 \mathrm{M} \mathrm{NaCl}$. Buffer $\mathrm{E}$ : the same as buffer D but lacking NP-40. Buffer F: the same as buffer E but with $300 \mathrm{mM} \mathrm{NaCl}$. Buffer G: the same as buffer $\mathrm{F}$ but with $170 \mathrm{mM}$ imidazole.

The cell pellet was resuspended in buffer $\mathrm{A}(\sim 5 \mathrm{~mL}$ buffer/g of cell pellet) supplemented with lysozyme, Complete, EDTA-free Protease Inhibitor Cocktail, AEBSF (100 $\mu \mathrm{M})$, and PMSF $(100 \mu \mathrm{M})$. Lysis was by sonication. After removal of cellular debris by centrifugation at $40000 \mathrm{~g}$ for $80 \mathrm{~min}$, the clarified lysate was transferred to a clean centrifuge bottle and "batched" with $7 \mathrm{~mL}$ of Talon cobalt resin for $30 \mathrm{~min}$ with gentle rocking. After the resin was pelleted, the supernatant was aspirated and the resin was batched a second time with $250 \mathrm{~mL}$ of fresh buffer A in an analogous manner. The resin was then transferred to a column that had been prepacked with $0.5 \mathrm{~mL}$ of fresh Talon resin. Washing was with $\sim 100 \mathrm{~mL}$ each of buffers B, C, D, and $\mathrm{E}$, in that order, using a peristaltic pump at a flow rate of $1.2 \mathrm{~mL} / \mathrm{min}$. Elution was performed at a similar flow rate using an increasing linear imidazole gradient consisting of $150 \mathrm{~mL}$ of buffer $\mathrm{F}$ and $150 \mathrm{~mL}$ of buffer $\mathrm{G}$, collecting $\sim 5$ $\mathrm{mL}$ fractions. ASFV APE eluted at $\sim 90 \%$ purity, as determined by SDS-PAGE with silver-staining, in a broad peak spanning 30-90 $\mathrm{mM}$ imidazole.

ASFV APE-containing fractions were pooled and supplemented with $10 \mathrm{mM}$ DTT prior to being diluted (with 50 $\mathrm{mM}$ Tris- $\mathrm{HCl}, 10 \%$ glycerol (v/v), $\mathrm{pH} \rightarrow 8.0$ with $\mathrm{KOH}$ while at $4{ }^{\circ} \mathrm{C}$, and $10 \mathrm{mM}$ DTT) to attain a final $\mathrm{NaCl}$ concentration of $65 \mathrm{mM}$. The diluted sample was immediately applied, by gravity flow, to a P-11 column (2.5 $\mathrm{cm}$ i.d.; $40 \mathrm{~mL}$ bed volume) that had been equilibrated with $50 \mathrm{mM}$ Tris- $\mathrm{HCl}, 75 \mathrm{mM} \mathrm{KCl}, 10 \%$ glycerol (v/v), $\mathrm{pH} \rightarrow$ 8.0 with $\mathrm{KOH}$ while at $4{ }^{\circ} \mathrm{C}$, and $10 \mathrm{mM}$ DTT. After washing with $350 \mathrm{~mL}$ of the same buffer, elution was effected by a linear $\mathrm{KCl}$ gradient consisting of $300 \mathrm{~mL}$ of the same buffer plus $300 \mathrm{~mL}$ of the same buffer containing $1 \mathrm{M} \mathrm{KCl}$; elution was run with a peristaltic pump at a flow rate of $0.7 \mathrm{~mL} /$ min, collecting $8.4 \mathrm{~mL}$ fractions. ASFV APE eluted at $95 \%$ purity in a peak spanning $250-425 \mathrm{mM} \mathrm{KCl}$.

Appropriate fractions were pooled and concentrated $\sim 13$ fold in an Amicon Ultra centrifugal filter device (5 kD MW cutoff). The small quantity of precipitate formed during concentration was removed by centrifugation before running the sample on an S-100 column $(200 \times 3 \mathrm{~cm}$ i.d. $)$ equilibrated with $50 \mathrm{mM}$ Tris- $\mathrm{HCl}, 150 \mathrm{mM} \mathrm{KCl}, 10 \%$ glycerol (v/v), $\mathrm{pH} \rightarrow 8.0$ with $\mathrm{KOH}$ while at $4{ }^{\circ} \mathrm{C}$, and 10 $\mathrm{mM}$ DTT. The flow rate was $0.86 \mathrm{~mL} / \mathrm{min}$, collecting 6.3 $\mathrm{mL}$ fractions. ASFV APE eluted with an apparent MW of $25.9 \mathrm{kD}$.

S-100 eluate was applied, by gravity flow, to a hydroxyapatite column ( $2.5 \mathrm{~cm}$ i.d.; $\sim 10 \mathrm{~mL}$ bed volume) that had been equilibrated with $20 \mathrm{mM} \mathrm{NaH} \mathrm{PO}_{4}, 10 \%$ glycerol (v/ v), pH 7.3 at $25{ }^{\circ} \mathrm{C}$, and $10 \mathrm{mM}$ DTT. Washing was with $100 \mathrm{~mL}$ of $80 \mathrm{mM} \mathrm{NaH} \mathrm{PO}_{4}, 10 \%$ glycerol (v/v), pH 7.3 at $25{ }^{\circ} \mathrm{C}, 10 \mathrm{mM}$ DTT, and $1 \%$ Tween 20 , followed by 100 $\mathrm{mL}$ of the same buffer containing $1 \%$ Triton X-100 instead of Tween 20, followed by $100 \mathrm{~mL}$ of the same buffer containing no detergent. Finally, elution was with $100 \mathrm{~mL}$ of $175 \mathrm{mM} \mathrm{NaH}{ }_{2} \mathrm{PO}_{4}, 10 \%$ glycerol (v/v), pH 7.3 at $25^{\circ} \mathrm{C}$, and $10 \mathrm{mM}$ DTT. While wash buffers were at $4{ }^{\circ} \mathrm{C}$, the elution buffer was at $20^{\circ} \mathrm{C}$ to prevent the sodium phosphate from crystallizing on the column.

Hydroxyapatite eluate was concentrated to $0.6 \mathrm{~mL}$ in an Amicon Ultra centrifugal filter device (5 kD MW cutoff) and then dialyzed into a buffer consisting of $50 \mathrm{mM}$ Trisborate, $100 \mathrm{mM} \mathrm{KCl}, 5 \%$ glycerol (v/v), $\mathrm{pH} 7.3$, and $1 \mathrm{mM}$ DTT using a Slide-a-Lyzer Dialysis cassette (3500 MW cutoff). After dialysis, enzyme-grade glycerol was added to achieve a final concentration of $40 \%$, and the protein was aliquoted and flash-frozen in liquid nitrogen before storage at $-80^{\circ} \mathrm{C}$. Subsequently, working stocks were kept at -20 ${ }^{\circ} \mathrm{C}$.

Determining the Size of Purified ASFV APE. Because ASFV APE, purified as described above, eluted from the gel filtration column with an anomalously low apparent molecular weight, its size was further characterized by both matrix-assisted laser desorption ionization time-of-flight (MALDI-TOF) mass spectrometry and Edman sequencing. A sample was prepared for mass spectrometry analysis by resolution on a $0.75 \mathrm{~mm}$ denaturing $12.5 \%$ polyacrylamide gel followed by fixing, staining with GelCode Blue, and excision of the protein band. Tryptic digestion and peptide identification were performed at the Ohio State CCIC facility. For Edman sequencing, the protein was run on a $0.4 \mathrm{~mm}$ thick denaturing $12.5 \%$ polyacrylamide gel followed by electroblotting to a PVDF membrane, which was then stained with Coomassie. The sequencing reactions were performed at Michigan State University's Macromolecular Structure Facility.

Determination of the Active Enzyme Concentration. Assays to determine the concentration of active ASFV APE were performed at $37{ }^{\circ} \mathrm{C}$ by mixing the protein solution (ASFV APE, at various dilutions, in buffer consisting of $50 \mathrm{mM}$ HEPES, $100 \mathrm{mM} \mathrm{KCl}, 15 \%$ glycerol (v/v), $\mathrm{pH} \rightarrow 7.8$ with $\mathrm{KOH}$ while at $37{ }^{\circ} \mathrm{C}, 600 \mu \mathrm{M}$ DTT, $3.0 \mathrm{mg} / \mathrm{mL} \mathrm{BSA}$, and $2 \mathrm{mM} \mathrm{MnCl}{ }_{2}$ ) with the substrate solution (400 nM A:THF in the same buffer but lacking DTT, BSA, and $\mathrm{MnCl}_{2}$ ) after preincubating both solutions at $37^{\circ} \mathrm{C}$ for $5 \mathrm{~min}$. When the reaction is initiated and quenched manually (i.e., with a pipet), ASFV APE displays biphasic kinetic behavior; the first turnover, completed within $8 \mathrm{~s}$ of reaction initiation and therefore inaccessible by manual quench techniques, is followed by a significantly slower steady state phase. Attempts to assess the pre-steady state time regime using rapid chemical quench were found to abolish the burst. We believe this phenomenon is due to inactivation of a large percentage of the protein by the turbulent mixing associated with reaction initiation. Accordingly, to approximate the active enzyme concentration, the steady state phase of a manual quench assay was subjected to linear regression and the $y$ intercept was multiplied by the enzyme dilution factor for that particular assay.

Activation of Purified ASFV APE by Exogenous Metal Ions. Purified ASFV APE was diluted to a concentration of 
$132 \mathrm{nM}$ in buffer consisting of $50 \mathrm{mM}$ HEPES, $100 \mathrm{mM}$ $\mathrm{KCl}, 15 \%$ glycerol (v/v), $\mathrm{pH} \rightarrow 7.8$ with $\mathrm{KOH}$ while at 37 ${ }^{\circ} \mathrm{C}, 3.0 \mathrm{mg} / \mathrm{mL} \mathrm{BSA}$, and the indicated metal ion at a concentration of either $400 \mu \mathrm{M}$ or $4 \mathrm{mM}$. The A:THF substrate was prepared as a $200 \mathrm{nM}$ solution in the same buffer but lacked BSA, DTT, and metal ion. After both the protein and the DNA solutions were preincubated at $37^{\circ} \mathrm{C}$ for $5 \mathrm{~min}, 40 \mu \mathrm{L}$ of protein solution was added to $40 \mu \mathrm{L}$ of DNA solution. After $15 \mathrm{~s}$, reactions were quenched and the products analyzed as described above.

The $\mathrm{Mn}^{2+}$ titration of purified ASFV APE was performed in a manner similar to that described in the preceding paragraph, except that 16 different metal ion concentrations were used (final values were $0,0.1,0.2,0.4,0.8,1.3,2,4$, $6,8,10,12,14,16,18$, and $20 \mathrm{mM}$ ), the premixing protein concentration was $26 \mathrm{nM}$, and reactions were quenched after 16 min.

3' Processing Assays. The 3'-phosphatase and 3' $\rightarrow 5^{\prime}$ exonuclease assays were performed in a manner analogous to the manual quench assay used for determining the active enzyme concentration, except that the postmixing concentrations of ASFV APE and the DNA substrates were 13 and $300 \mathrm{nM}$, respectively. At appropriate time points, $10 \mu \mathrm{L}$ aliquots were quenched by mixing with $10 \mu \mathrm{L}$ of formamide, followed by resolution on $19 \%$ denaturing polyacrylamide gels and visualization as described above.

The substrate for the 3'-phosphodiesterase assay was prepared as follows. A total of 51 pmol of the A:U duplex (see Figure 1) was incubated with 4 units of uracil DNA glycosylase (UDG) for $45 \mathrm{~min}$ at $37^{\circ} \mathrm{C}$ in a buffer consisting of $50 \mathrm{mM}$ HEPES, $100 \mathrm{mM} \mathrm{KCl}, 15 \%$ glycerol (v/v), $\mathrm{pH}$ $\rightarrow 7.8$ with $\mathrm{KOH}$ while at $37{ }^{\circ} \mathrm{C}, 770 \mu \mathrm{M}$ DTT, $1.28 \mathrm{mM}$ EDTA, and $3.85 \mathrm{mg} / \mathrm{mL}$ BSA (total volume $=77 \mu \mathrm{L}$ ). A total of 40 units $(4 \mu \mathrm{L})$ of endonuclease III (which possesses AP lyase activity) was then added, and incubation continued for 15 min before adding a 10\% molar excess of UDG inhibitor $(4.2 \mu \mathrm{L})$ and incubating another $60 \mathrm{~min}$. This DNA, now containing a single nucleotide gap flanked by a 5'-phosphate and 3'-4-hydroxy-2-pentenal-5-phosphate, was incubated at a concentration of $300 \mathrm{nM}$ with $13 \mathrm{nM}$ ASFV APE in a buffer whose final composition was $50 \mathrm{mM}$ HEPES, $100 \mathrm{mM} \mathrm{KCl,} \mathrm{15 \%} \mathrm{glycerol} \mathrm{(v/v),} \mathrm{pH} \rightarrow 7.8$ with $\mathrm{KOH}$ while at $37{ }^{\circ} \mathrm{C}, 300 \mu \mathrm{M}$ DTT, $195 \mu \mathrm{M}$ EDTA, 1.5 $\mathrm{mg} / \mathrm{mL} \mathrm{BSA}$, and $1.195 \mathrm{mM} \mathrm{Mn}{ }^{2+}$. Because we and others (39) have found that the 3'-4-hydroxy-2-pentenal-5-phosphate moiety reacts with Tris during electrophoresis, reactions were quenched and the aldehyde simultaneously reduced via the following protocol. At the indicated time points, aliquots were withdrawn, supplemented with sodium borohydride $\left(\mathrm{NaBH}_{4}\right)$ to a final concentration of $285 \mathrm{nM}$, and then placed on ice. After incubation on ice for at least $30 \mathrm{~min}$, tRNA and ammonium acetate were added to concentrations of 0.06 $\mu \mathrm{g} / \mathrm{mL}$ and $2.5 \mathrm{M}$, respectively. Ethanol was then added to achieve a concentration of $70 \%$, and the DNA was allowed to precipitate for at least $30 \mathrm{~min}$ on ice. After pelleting the DNA at $4{ }^{\circ} \mathrm{C}$ in a microfuge for at least $20 \mathrm{~min}$, the supernatant was aspirated and the pellet allowed to air dry prior to being resuspended in formamide. Samples were resolved on a 19\% denaturing polyacrylamide gel and visualized as above.

NIR Assay. ASFV APE was probed for NIR activity against 5,6-dihydrothymine in a manner analogous to the

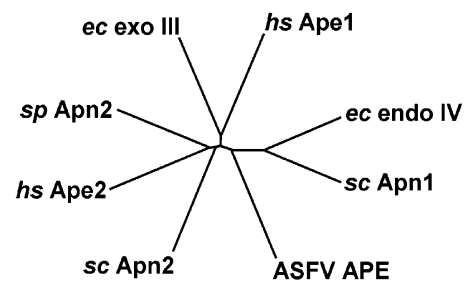

FIGURE 2: Unrooted phylogenetic tree showing the relationship between the putative ASFV APE protein and APEs from both the endonuclease IV and exonuclease III protein families. The endonuclease IV family is represented by $E$. coli endonuclease IV (ec endo IV) and S. cerevisiae Apn1 (sc Apn1). The exonuclease III family is represented by $E$. coli exonuclease III (ec exo III), $H$. sapiens Ape1 (hs Ape1), H. sapiens Ape2 (hs Ape2), S. cerevisiae Apn2 (sc Apn2), and S. pombe Apn2 (sp Apn2). Note that $h s$ Ape2, $s c$ Apn2, and sp Apn2 contain unique C-terminal extensions and therefore represent a distinct subfamily within the exonuclease III family of proteins (58). See the Experimental Procedures for details of tree construction.

manual quench assay used for determining the active enzyme concentration, except that the postmixing concentrations of ASFV APE and DNA substrate were 130 and $300 \mathrm{nM}$, respectively. E. coli endonuclease IV, at a final concentration of $520 \mathrm{nM}$, was assayed in an analogous manner to serve as a positive control.

Pol X-Catalyzed Gap-Filling Assays. Polymerase reactions were performed with a KinTek RQF-3 rapid chemical quench apparatus at $37{ }^{\circ} \mathrm{C}$. Syringe A contained $150 \mathrm{nM}$ Pol X [expressed, purified, and quantitated essentially as described previously (30)] and $400 \mathrm{nM}$ gapped $\mathrm{G}$ substrate in buffer consisting of $50 \mathrm{mM}$ Tris-borate, $50 \mathrm{mM} \mathrm{KCl}, 3 \%$ glycerol $(\mathrm{v} / \mathrm{v}), \mathrm{pH} \rightarrow 9.0$ with $\mathrm{KOH}$ while at $25^{\circ} \mathrm{C}, 2 \mathrm{mM}$ DTT, and $200 \mu \mathrm{g} / \mathrm{mL}$ BSA. Syringe B contained $18 \mathrm{mM}$ dCTP (to give $9 \mathrm{mM}$ postmixing; this high concentration of nucleotide is necessary for saturating the enzyme, which displays a $K_{\text {d,app }}$ of $\sim 1 \mathrm{mM}$ for the $\mathrm{G}: \mathrm{C}$ base pair under these conditions) and $18.97 \mathrm{mM} \mathrm{MgCl}_{2}$. The $5^{\prime}$ moiety of the gapped substrate was either phosphate or the tetrahydrofuran $5^{\prime}$-dRP analogue $5^{\prime}-\mathrm{P}_{\mathrm{i}}$-THF. Reactions were quenched with $600 \mathrm{mM} \mathrm{Na} \mathrm{Na}_{2}$ EDTA (pH 8.0), followed by resolution on $19 \%$ denaturing gels and visualization/analysis as described above.

\section{RESULTS}

Sequence Alignment and Phylogenetic Tree. Phylogenetic analysis of known AP endonucleases results in a bifurcation between proteins similar to $E$. coli exonuclease III and proteins similar to E. coli endonuclease IV (9). Although both protein families catalyze hydrolysis of the phosphodiester bond $5^{\prime}$ to AP sites, they do so via dissimilar mechanisms; exonuclease III employs a single readily dissociatable magnesium ion (10), while endonuclease IV utilizes three tightly bound zinc ions (11). Sequence alignments reveal the putative ASFV APE to be $21 \%$ similar (14\% identical) to exonuclease III and $24 \%$ similar (17\% identical) to endonuclease IV, hence the branching pattern of the unrooted phylogenetic tree in Figure 2. Despite its greater similarity to endonuclease IV, the putative ASFV APE is not especially dissimilar to exonuclease III; this is likely the reason that the ASFV protein was previously described as an Ape1 (the human counterpart of exonuclease III) homologue (40). Support for the putative ASFV APE being a true endonuclease IV homologue is the fact that eight of the nine 
E. coli endo IV S. cerevisiae Apn1 ASFV APE

E. coli endo IV S. cerevisiae Apn1 ASFV APE

E. coli endo IV S. Cerevisiae Apn1 ASFV APE

E. coli endo IV S. Cerevisiae Apn1 ASFV APE

E. coli endo IV S. Cerevisiae Apn1 ASFV APE

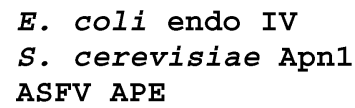

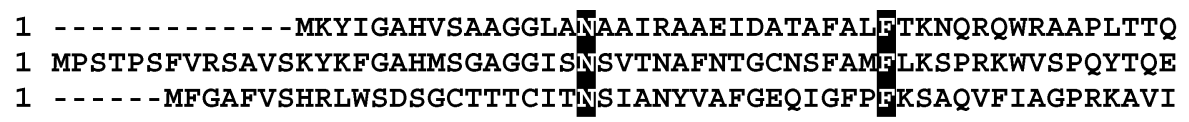
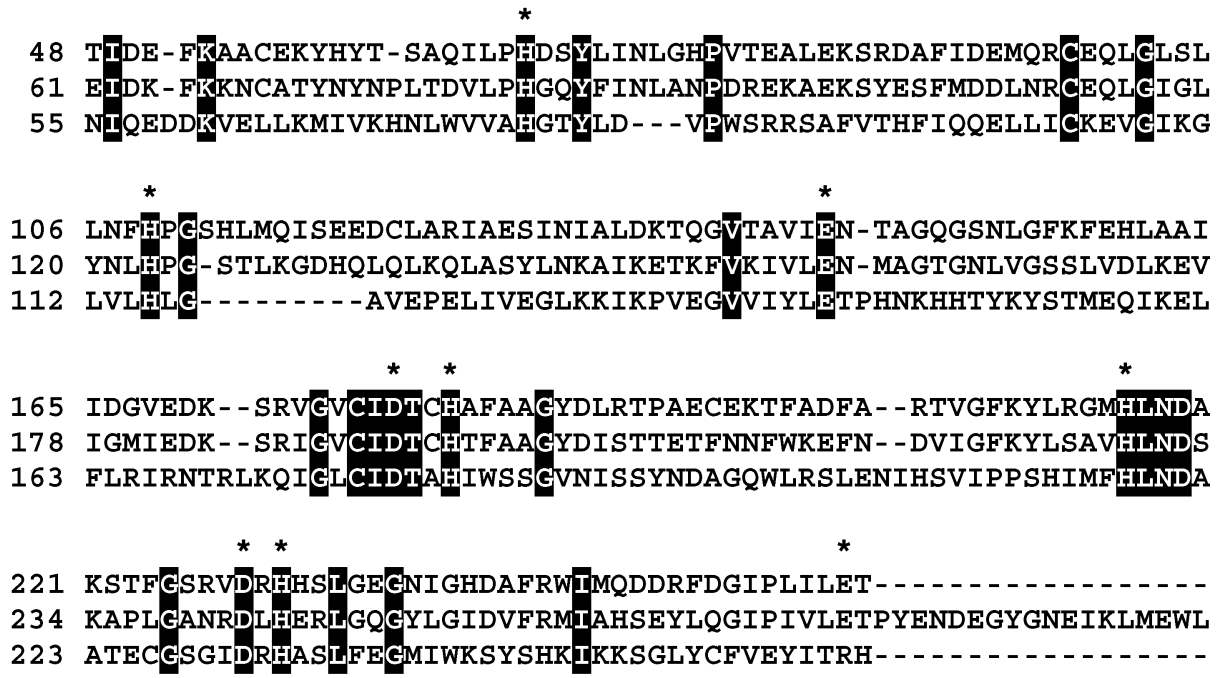
YLIGHDAFRW 234 KAPLEANRDLFER 23 ATECGSIDRHASLFEGMIWKSYSHKIKKSGLYCFVEYITRH - .
E. coli endo IV S. cerevisiae Apn1 ASFV APE

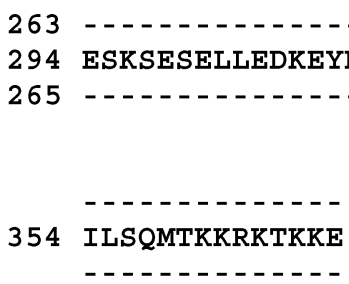

FIGURE 3: Sequence alignment of E. coli endonuclease IV with two of its homologues, $S$. cerevisiae Apn1 and the putative APE from ASFV. Identical residues are highlighted in black. Asterisks mark the nine residues in endonuclease IV that coordinate its three catalytic zinc ions. See the Experimental Procedures for details of alignment construction.

zinc-coordinating residues in endonuclease IV are conserved in the viral protein (Figure 3). In contrast, conservation of active site residues between exonuclease III and the putative ASFV APE is less extensive (data not shown).

Testing the Putative ASFV APE for Endonuclease IV-Like Activities by Complementation. To test for endonuclease IVlike activities in the putative ASFV APE, we asked whether the viral protein could complement APE-deficient $E$. coli (the $n f o^{-} x t h^{-}$strain BL100) upon exposure to two different DNA-damaging agents. Because of its capacity to methylate purines and thereby promote depurination (2), MMS was used to probe for APE activity; tert-butyl hydroperoxide was chosen because the radical species generated by peroxides can give rise to DNA single-strand breaks with polymerase/ ligase-unusable 3'-blocking groups (12) (3'-phosphodiesterase substrates) in addition to $\alpha$-anomeric nucleotides and ringsaturated pyrimidines (NIR substrates) $(41,42)$. Parts A and $\mathrm{B}$ of Figure 4 demonstrate that at the highest drug concentrations tested expression of ASFV gene E296R confers an 18fold (MMS) and 620-fold (tert-butyl hydroperoxide) fitness advantage relative to cells lacking the viral gene. This complementation is consistent with the product of ASFV gene E296R possessing APE and 3'-phosphodiesterase (and/ or NIR) activities. Accordingly, the protein will henceforward be referred to as ASFV APE.

Metal Ion Requirements of Crude ASFV APE. If ASFV APE is a functional homologue of endonuclease IV, it is expected to be active in the absence of exogenous metal ions and to resist inactivation by chelating agents when a substrate is present (13). Figure 5 demonstrates that, in the presence of $500 \mu \mathrm{M}$ EDTA, cell-free extract prepared from BL100 cells overexpressing ASFV APE displays canonical APE activity; the 45mer duplex A:THF substrate is incised $5^{\prime}$ to the THF abasic site analogue to generate a 25 mer product (see Figure 1 for details of the substrate structure). That this activity may be specifically attributed to ASFV APE is confirmed by the absence of such activity in cells lacking the pET21-ASFV APE expression plasmid (parts A and B of Figure 5).

To discern whether ASFV APE possesses tightly bound metal cofactors similar to endonuclease IV and its homologues (43), we attempted to inactivate the viral protein by preincubating it at $50{ }^{\circ} \mathrm{C}$ in the presence of the metal chelator 1,10-phenanthroline before adding the A:THF substrate. As seen in Figure 6A, when incubated with either no phenanthroline isomer or the nonchelating 1,7 isomer, ASFV APE displays a linear loss in activity as a function of the length of preincubation at $50{ }^{\circ} \mathrm{C}$. In contrast, the presence of the chelating 1,10-phenanthroline results in $\sim 90 \%$ loss of activity even without preincubation at $50{ }^{\circ} \mathrm{C}$. Collectively, the above results suggest that the activity of ASFV APE, although not requiring exogenous metal ions, is indeed dependent upon an intrinsic metal cofactor(s).

After being subjected to purification both endonuclease IV and its yeast homologue Apn1 can be stimulated by the addition of exogenous metal ions (43), suggesting the partial loss of metal cofactors from their active sites during purification and/or the absence of the full complement of 

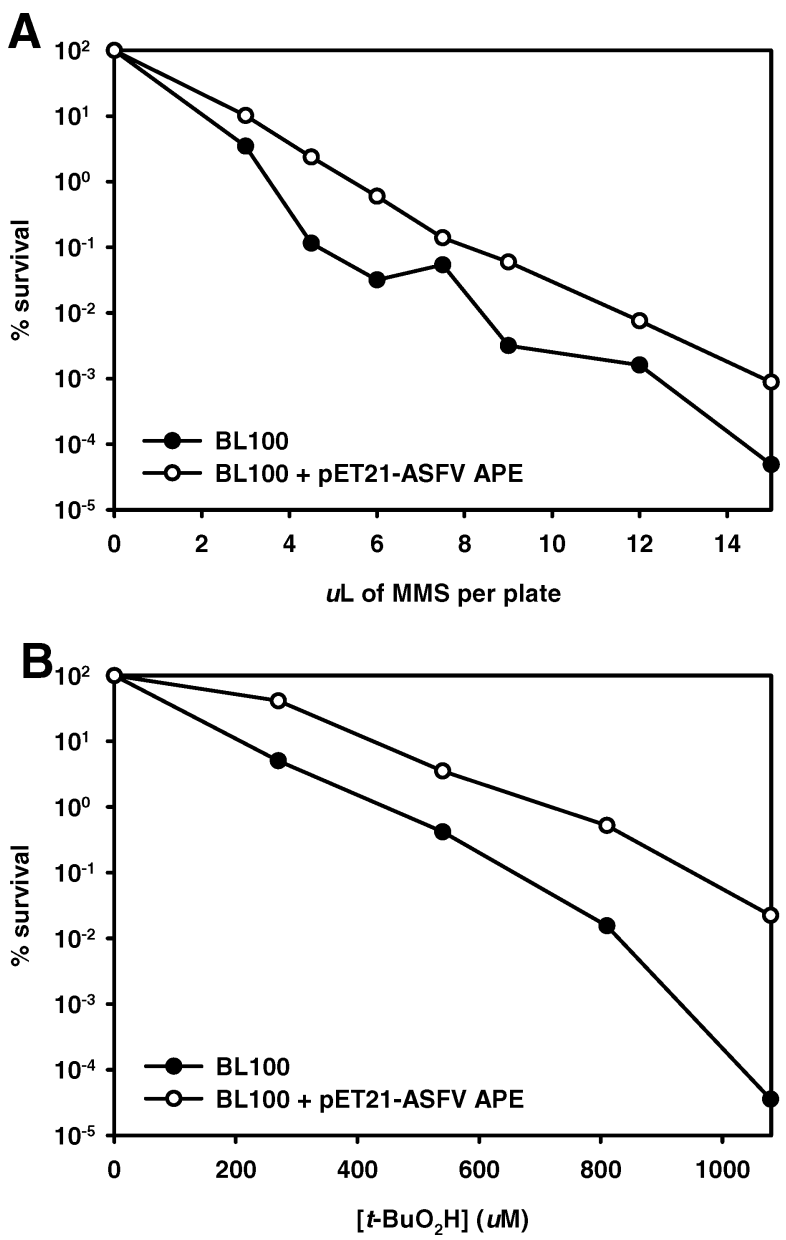

FIGURE 4: In an APE-deficient genetic background, expression of ASFV gene E296R promotes survival during chronic exposure to both MMS and peroxide. BL100 cells, containing or lacking the pET21-ASFV APE expression plasmid, were grown to mid-log phase, induced with IPTG for $2 \mathrm{~h}$, and then mixed with molten top agarose containing the indicated concentration of DNA-damaging agent before being plated on LB agar supplemented with $1 \mathrm{mM}$ IPTG. (A) Percent survival as a function of the quantity (in microliters) of MMS added per plate. (B) Percent survival as a function of tert-butyl hydroperoxide concentration. Percent survival is defined as (the number of colonies per plate in the presence of DNA-damaging agent/the number of colonies per plate in the absence of DNA-damaging agent) $\times 100$. Note the logarithmic scale for the $y$ axes.

metal ions after overexpression. To assess whether ASFV APE, upon overexpression in BL100 cells, contains its full complement of catalytic metal ions, the activity of ASFV APE-containing cell-free extract was examined in the absence and presence of seven different divalent metal ions (Figure $6 \mathrm{~B})$. None of the metal ions examined was able to stimulate the activity of crude ASFV APE; in fact, all but $\mathrm{Ca}^{2+}$ inhibited APE activity. We conclude that after overexpression in BL100 cells the active site of ASFV APE is either saturated with metal cofactors or, if that is not the case, the conditions of the assay do not permit the assembly of a catalytically competent active site.

Characterizing the Size of Purified ASFV APE. Having performed the above assays in vivo and with cell-free extracts, we next sought to study the purified protein. As described in the Experimental Procedures, partially purified ASFV APE (34.5 kD theoretical MW) eluted from a gel filtration column at the anomalously low apparent MW of
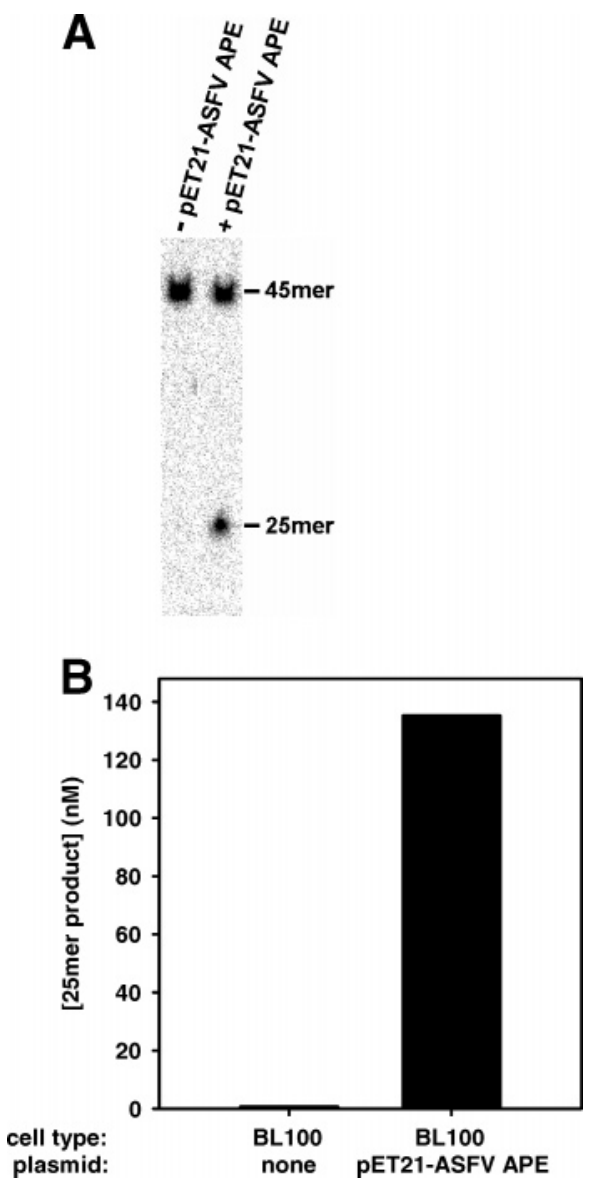

FIGURE 5: Expression of ASFV gene E296R correlates with the appearance of an EDTA-resistant AP endonuclease activity in BL100 cells. Lysate from cells containing or lacking the pET21ASFV APE expression plasmid was incubated with $400 \mathrm{nM}$ A:THF substrate in the presence of $500 \mu \mathrm{M}$ EDTA at $37{ }^{\circ} \mathrm{C}$ for $90 \mathrm{~min}$. (A) DNA-sequencing gel demonstrating the absence and presence of a canonical APE activity (incising $5^{\prime}$ to the AP site analogue) in cells lacking or containing the pET21-ASFV APE expression plasmid, respectively. (B) Quantitative depiction of data from the gel in A.

$25.9 \mathrm{kD}$. Because this construct bound tightly to the Talon cobalt column, it was expected that the $\mathrm{C}$ terminus (containing the $\mathrm{His}_{6}$ tag) was intact but that the $\mathrm{N}$ terminus might be truncated. Tryptic digestion coupled with MALDI-TOF mass spectrometry identified the following peptides: ${ }^{41} \mathrm{SAQV}$ FIAGPRKAVINIQEDDKVELLK ${ }^{66}$ and ${ }^{252}$ SGLYCFVEYITRHQCPAI LERNLGSSMQLQTALTAEFTTLK ${ }^{292}$. Although the latter confirmed an intact $\mathrm{C}$ terminus, the integrity of the $\mathrm{N}$ terminus remained ambiguous. The protein was therefore subjected to Edman sequencing. The first five $\mathrm{N}$-terminal residues were determined to be MFGAF, indicating that the protein is in fact full-length.

Metal Ion Dependence of Purified ASFV APE. In contrast to what was observed with ASFV APE-containing cell-free extract, purified ASFV APE is activated roughly 2-fold by both $200 \mu \mathrm{M}$ and $2 \mathrm{mM} \mathrm{Co}^{2+} ; \mathrm{Mn}^{2+}$ activates the protein to a similar extent, although only at the higher metal ion concentration (Figure 7A); see the Discussion for an explanation regarding the different affects of metal ions on the crude and purified forms of the protein. In a similar type of assay, $\mathrm{Co}^{2+}$ was found to activate both endonuclease IV and Apn1 to an extent similar to that observed here for the ASFV protein $\mathrm{Mn}^{2+}$ was not examined in the same manner 

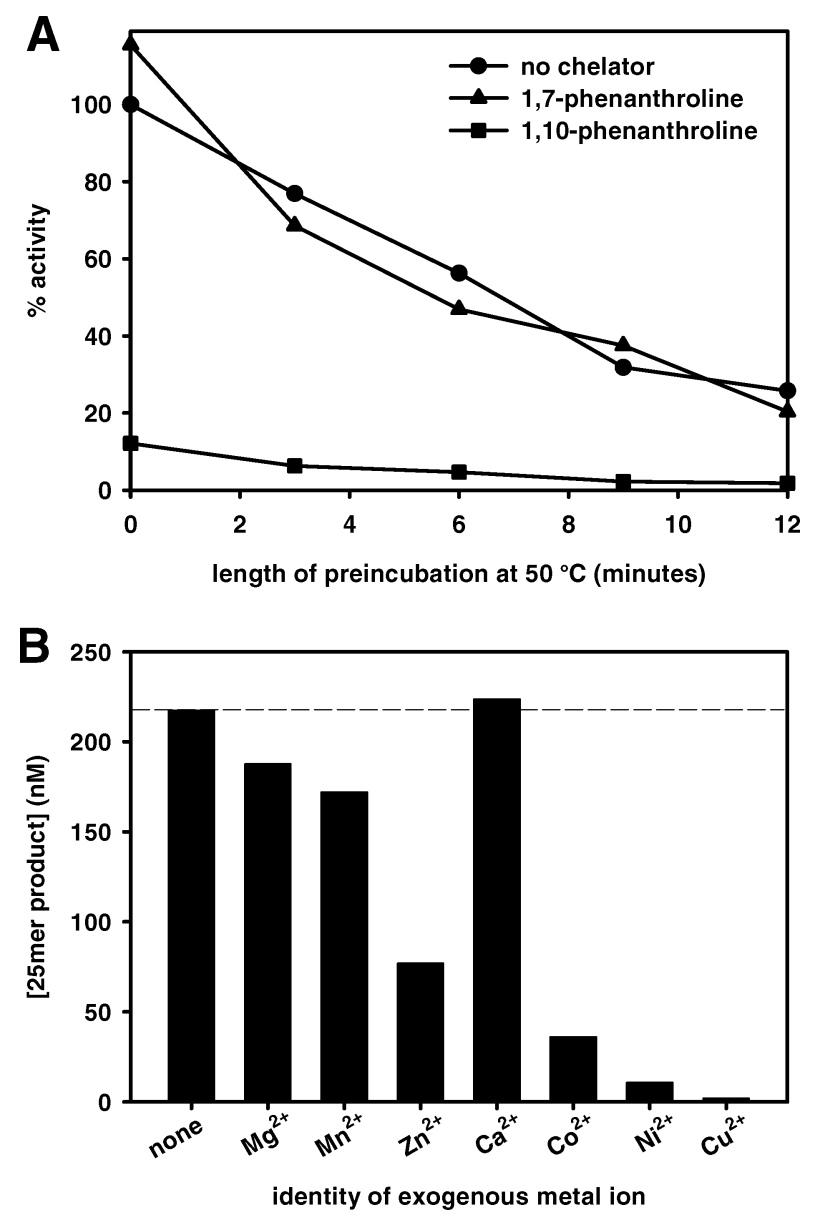

FIGURE 6: Metal dependence of crude ASFV APE. (A) Inactivation of crude ASFV APE upon heating in the presence of a metal chelator. Cell-free extract from BL100 cells expressing protein from the pET21-ASFV APE plasmid was incubated with $400 \mathrm{nM} \mathrm{A:THF}$ substrate at $37^{\circ} \mathrm{C}$ for $20 \mathrm{~s}$ followed by quenching with formamide. Prior to incubation with the DNA substrate, the cell-free extract was incubated at $50{ }^{\circ} \mathrm{C}$ for the indicated amount of time in the presence of $600 \mu \mathrm{M}$ 1,7-phenanthroline (nonchelating), $600 \mu \mathrm{M}$ 1,10-phenanthroline (chelating), or in the absence of a phenanthroline isomer. Percent activity is defined as (the concentration of product for the reaction of interest/the concentration of product for the reaction that was not preincubated at $50{ }^{\circ} \mathrm{C}$ and did not contain a phenanthroline isomer) $\times 100$. (B) Crude ASFV APE is not activated by exogenous metal ions. Cell-free extract from BL100 cells expressing protein from the pET21-ASFV APE plasmid was supplemented with the indicated metal ion (1 mM final concentration) and incubated with $400 \mathrm{nM} \mathrm{A:THF}$ substrate at $37{ }^{\circ} \mathrm{C}$. Quenching was with formamide after $20 \mathrm{~s}$. The dashed, horizontal line denotes the height of the bar from the control reaction, which did not contain exogenous metal ion.

for the E. coli and yeast proteins) (43). In contrast to $\mathrm{Co}^{2+}$ and $\mathrm{Mn}^{2+}$, we have consistently found $\mathrm{Mg}^{2+}, \mathrm{Ni}^{2+}, \mathrm{Ca}^{2+}$, and $\mathrm{Zn}^{2+}$ to inhibit the ASFV protein, although to different extents.

Because a future objective is to study the complete, reconstituted ASFV DNA repair pathway and because $\mathrm{Mn}^{2+}$ is known to be well-tolerated by both DNA polymerases $(44-46)$ and DNA ligases $(47,48),{ }^{4}$ we decided to include $\mathrm{Mn}^{2+}$ in the ASFV APE assay buffer and a titration was performed to determine its optimal concentration. On the basis of the data in Figure 7B, $1 \mathrm{mM} \mathrm{Mn}^{2+}$ was included in all subsequent assays.

3' Processing and NIR Activities of ASFV APE. As described above, endonuclease IV and its homologues are
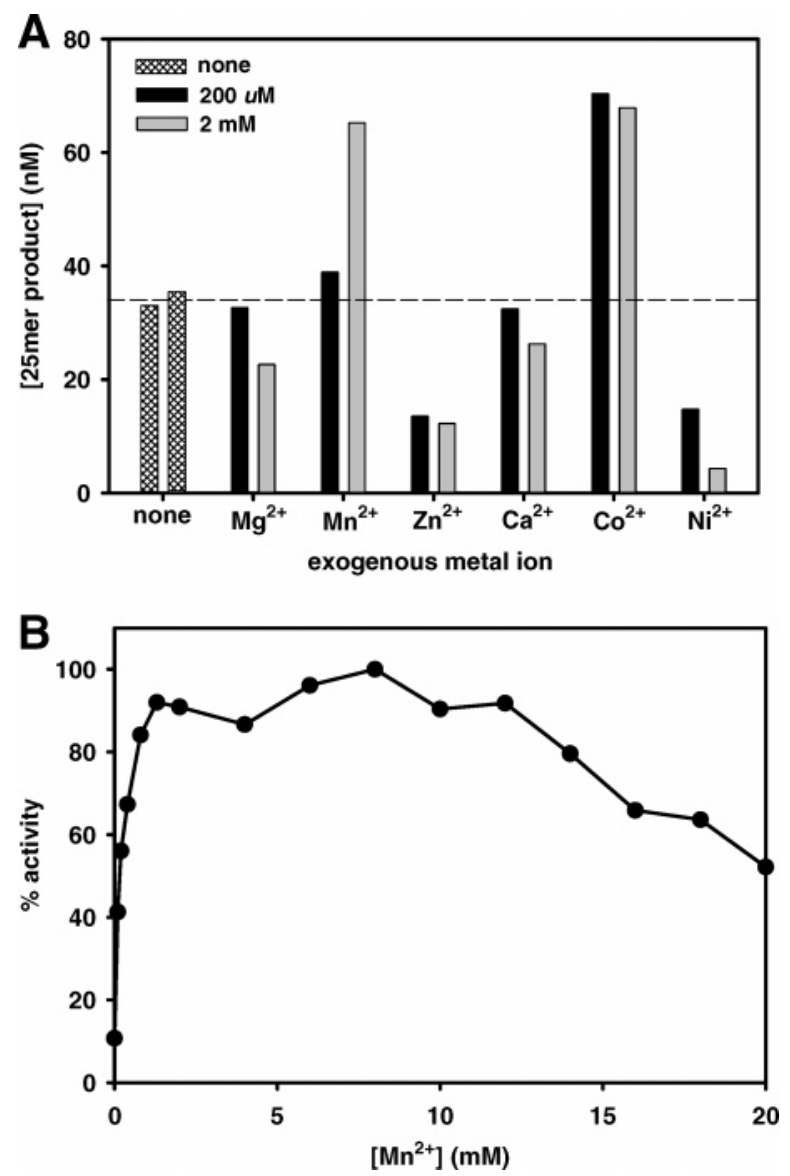

FIGURE 7: Metal preference of purified ASFV APE. (A) Activity of purified ASFV APE as a function of exogenous metal ion identity. ASFV APE $(66 \mathrm{nM})$, without exogenous metal ion or supplemented with either $200 \mu \mathrm{M}$ or $2 \mathrm{mM}$ of the indicated metal ion, was incubated with $100 \mathrm{nM} \mathrm{A}$ :THF substrate at $37{ }^{\circ} \mathrm{C}$ for 15 $\mathrm{s}$ before quenching with formamide. The dashed, horizontal line denotes the average bar height from two independent assays performed in the absence of exogenous metal ion. (B) $\mathrm{Mn}^{2+}$ titration. ASFV APE $(13 \mathrm{nM})$ was supplemented with $\mathrm{MnCl}_{2}$ at the indicated concentration and incubated with $100 \mathrm{nM}$ A:THF substrate at $37^{\circ} \mathrm{C}$ for 16 min before quenching with formamide.

endowed with numerous activities for processing 3' lesions that keep DNA refractory to polymerization and/or ligation (9). ASFV APE was assayed for the 3' processing activities expected to be relevant to the ASFV DNA repair pathway. Figure 8 demonstrates that in the context of a single-nucleotide gap ASFV APE possesses 3'-phosphatase and $3^{\prime}$-phosphodiesterase activities (parts A and B, respectively), whereas, in the context of a nick, the enzyme is capable of acting as a $3^{\prime} \rightarrow 5^{\prime}$ exonuclease (part C). This latter activity is most appropriately described as "nickediting" because excision does not efficiently proceed beyond the nascent $3^{\prime}$ nucleotide of the nick (i.e., gaps do not appear to be optimal substrates) and mismatched nucleotides are removed preferentially. It is interesting to note that the efficiency of nick-editing is highly dependent upon the identity of the nascent $3^{\prime}$ base pair, with the A:G mismatch

${ }^{4}$ There are admittedly caveats regarding reduced fidelity, for both polymerases and ligases, in the presence of $\mathrm{Mn}^{2+}$ [Weymouth, L. A., and Loeb, L. A. (1978) Mutagenesis during in vitro DNA synthesis, Proc. Natl. Acad. Sci. U.S.A. 75, 1924-1928; Tong, J., Cao, W., and Barany, F. (1999) Biochemical properties of a high fidelity DNA ligase from Thermus species AK16D, Nucleic Acids Res. 27, 788-794]. 
A
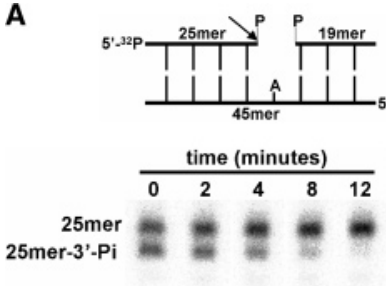

B
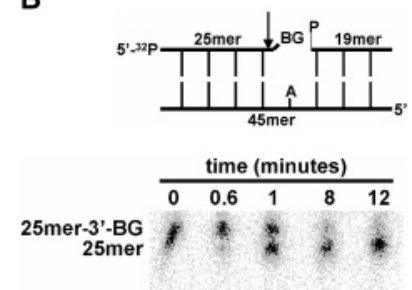

D

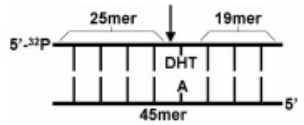

C
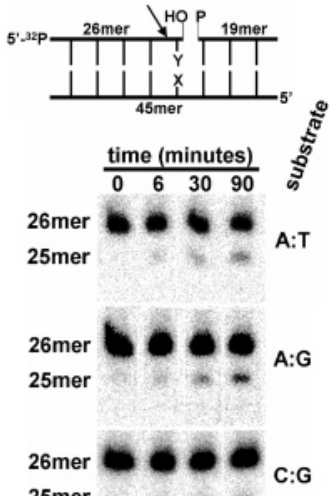

25mer

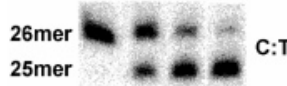

analogue of $5^{\prime}$-dRP $\left(5^{\prime}-\mathrm{P}_{\mathrm{i}}-\mathrm{THF}\right)^{5}$ are shown in Figure 10. Burst assays were employed with Pol $\mathrm{X}$ because this allowed an evaluation of the pre-steady state in addition to the steady state. While the pre-steady state rate is virtually unaffected [0.25 $\mathrm{s}^{-1}$ (5'-phosphate) versus $\left.0.23 \mathrm{~s}^{-1}\left(5^{\prime}-\mathrm{P}_{\mathrm{i}}-\mathrm{THF}\right)\right]$, replacing $5^{\prime}$-phosphate with $5^{\prime}-\mathrm{P}_{\mathrm{i}}$-THF increases the steady state rate $\sim 5$-fold ( 0.98 versus $0.19 \mathrm{nM} / \mathrm{s}$ ) (Figure 10A), presumably by increasing the rate of product release. Whether these different $5^{\prime}$ moieties uniquely affect the error-proness of Pol $\mathrm{X}$ has not yet been examined. The influence of $5^{\prime}-\mathrm{P}_{\mathrm{i}}-\mathrm{THF}$ on ASFV APE nick-editing varies dramatically depending upon the identity of the $3^{\prime}$ base pair of the nick. While C:T is edited $\sim 15$-fold more efficiently in the presence of $5^{\prime}$-phosphate than in the presence of $5^{\prime}-\mathrm{P}_{\mathrm{i}}-\mathrm{THF}$, the difference for editing $\mathrm{A}: \mathrm{G}$ is less than 2-fold (parts B and $\mathrm{C}$ of Figure 10).

\section{DISCUSSION}

ASFV Gene E296R Is a Functional Homologue of Endonuclease $I V$. The ability of the protein product of ASFV gene E296R to promote the survival of APE-deficient E. coli under chronic exposure to MMS and tert-butyl hydroperoxide (Figure 4) implies a capacity for processing AP sites and either 3'-blocked single-strand breaks or $\alpha$-anomeric nucleotides/ring-saturated pyrimidines. The in vitro assays with purified protein and oligonucleotide substrates unequivocally establish its AP endonuclease, $3^{\prime}$-phosphatase, $3^{\prime}$-phosphodiesterase, $3^{\prime} \rightarrow 5^{\prime}$ exonuclease, and NIR activities (Figures 7 and 8) and validate its classification as a canonical APE.

Conservation of endonuclease IV zinc-coordinating residues in ASFV APE (Figure 3), the activity of the viral protein in the presence of EDTA (Figure 5), and the inactivation of the viral protein by incubation with 1,10-phenanthroline in the absence of a substrate (Figure 6A) all suggest that ASFV APE is a functional homologue of endonuclease IV, possessing intrinsic metal cofactors. When purified in the absence of a metal chelator, ASFV APE, similar to endonuclease IV (43), is activated by $\mathrm{Co}^{2+}$ but not $\mathrm{Zn}^{2+}-$ which is presumed to be its native cofactor (Figure 7A). Though a specific explanation for the inability of exogenous $\mathrm{Zn}^{2+}$ to activate these proteins is lacking, $\mathrm{Co}^{2+}$ has been empirically demonstrated to serve as a functional substitute for $\mathrm{Zn}^{2+}$ in numerous enzymes $(51,52)$. The identification by atomic absorption spectroscopy of substoichiometric yet significant quantities of manganese in endonuclease IV (43) and the ability of $\mathrm{Mn}^{2+}$ to activate endonuclease IV after inactivation by either EDTA or 1,10-phenanthroline (43) are consistent with the manganese activation of purified ASFV APE observed here.

The activation of purified ASFV APE by manganese and cobalt (Figure 7A) stands in contrast to the moderate and strong, respectively, inhibition exerted by these metals on ASFV APE-containing cell-free extract (Figure 6B). This apparent discrepancy might best be accounted for by nonspecific affects in the cell-free extract, such as inactivation of ASFV APE by a metalloprotease; an alternative explanation, that the A:THF substrate was rendered unusable by an $E$. coli protein, seems unlikely since the electrophoretic properties of the substrate were unperturbed.

APE can potentially function within two different substrate contexts. We asked how the gap-filling and nick-editing activities are influenced when $\mathrm{dRP}$, rather than phosphate, is the $5^{\prime}$ moiety of a gap or nick. Assays employing the THF

${ }^{5}$ Because this lacks the $\mathrm{C}^{\prime}$ hydroxyl of $\mathrm{dRP}$, it is not prone to spontaneous $\beta$-elimination. 


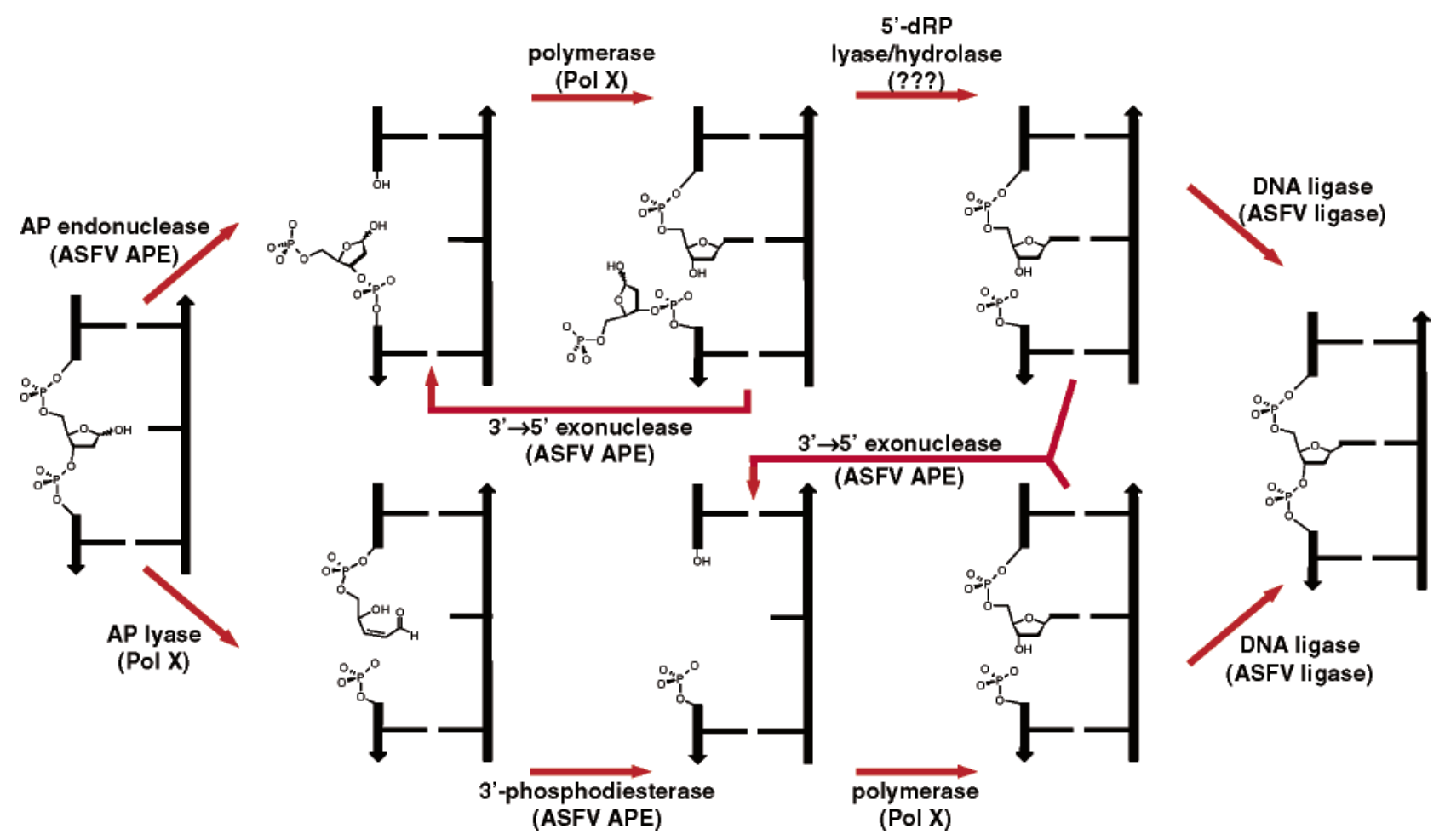

FIGURE 9: Abasic site repair by ASFV proteins.

ASFV APE differs from its $E$. coli counterpart in its thermal stability. Whereas a $12 \mathrm{~min}$ incubation at $50{ }^{\circ} \mathrm{C}$ caused a $70 \%$ loss in ASFV APE activity (Figure 6A), 20 min at $50{ }^{\circ} \mathrm{C}$ caused just a $0-20 \%$ decrease in the diesterase activity of endonuclease IV (13). Since this apparent difference in thermal stability is not likely to be artifactual (the buffer systems employed in these different studies were very similar), it would appear that the $65^{\circ} \mathrm{C}$ incubation commonly employed in endonuclease IV purification protocols (53) is inappropriate for the ASFV enzyme.

Potential Biological Functions of ASFV APE. The characterization of ASFV APE presented here improves our understanding of the capabilities of the ASFV-encoded DNA repair pathway, and this in turn provides clues about the types of damage likely sustained by the viral genome. If the ASFV genome experiences oxidative damage, ${ }^{6}$ the ASFV APE gene might have been retained primarily for its $3^{\prime}$-phosphodiesterase activity, which could convert $3^{\prime}$-blocked singlestrand breaks (such as 3'-phosphoglycolate) into 3'-hydroxyl termini usable by Pol X. The activity of ASFV APE against 3 '-phosphoglycolate has not yet been examined, but on the basis of its structural similarity to the efficiently excised $3^{\prime}$ 4-hydroxy-2-pentenal-5-phosphate (Figures 1 and 8B), this lesion is almost certainly within the enzyme's repertoire of substrates.

Although it awaits experimental verification, the NIR activity of ASFV APE against 5,6-dihydrothymine implies a capacity to also process $\alpha$-anomeric nucleotides and ringfragmented purines $(18,21)$. Recent data suggests that some of the lesions constituting NIR substrates may be relatively abundant in genomic DNA (41); however, the extent to which these lesions are formed in the ASFV genome (which

${ }^{6}$ The presence of MutT (a nudix hydrolase that cleanses the nucleotide pool of 8-oxo-dGTP) in the ASFV genome suggests that the virus may be forced to contend with oxidative DNA damage. occupies both the nucleus and the cytoplasm of the host during different phases of viral maturation) is unstudied. The presence of NIR activity in ASFV APE may account for the absence of an ASFV-encoded DNA glycosylase (23): by cleaving $5^{\prime}$ to the nucleotide with the damaged base, NIR obviates the necessity of damaged base removal. The problem, however, with this scenario is that following gap-filling by Pol $\mathrm{X}$ the nascent $5^{\prime}$-dangling nucleotide would need to be removed prior to nick ligation and an appropriate activity (such as that provided by FEN1) is apparently absent in ASFV (23). If NIR-processible lesions occur infrequently in the viral genome or if the NIR activity of ASFV APE is inefficient (as our data suggests), then metabolic dead ends resulting from persistent $5^{\prime}$-dangling nucleotides might be insignificant. Alternatively, ASFV may in fact encode an as of yet unidentified FEN1-like activity or simply recruit this activity from the host.

In the absence of an ASFV DNA glycosylase, the ASFV APE gene may have been retained for the purpose of processing AP sites resulting from spontaneous, rather than glycosylase-mediated, base loss; note that spontaneous depurination is common even under normal metabolic conditions (54). Catalytic parameters are not yet available, but a semiquantitative comparison of AP site hydrolysis by ASFV APE with the AP lyase activity of Pol X (40) suggests that the former route (the upper pathway in Figure 9) is likely to be used almost exclusively. This poses an apparent problem in that an ASFV protein capable of removing the $5^{\prime}$-dRP generated by ASFV APE has not yet been identified; unlike its eukaryotic counterpart, $\operatorname{Pol} \beta, \operatorname{Pol} \mathrm{X}$ is incapable of acting as a $5^{\prime}$-dRP lyase (40). Although $5^{\prime}$-dRP is labile because of its susceptibility to $\beta$-elimination, the half-life for this reaction under physiological conditions is on the order of $30 \mathrm{~h}$ (55). That such a bottleneck in the pathway would be tolerated seems unlikely, and efforts to identify a 


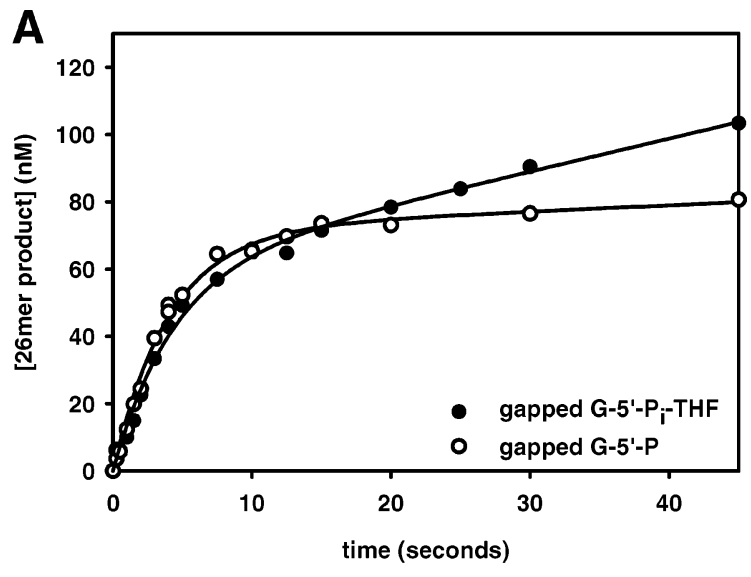

B
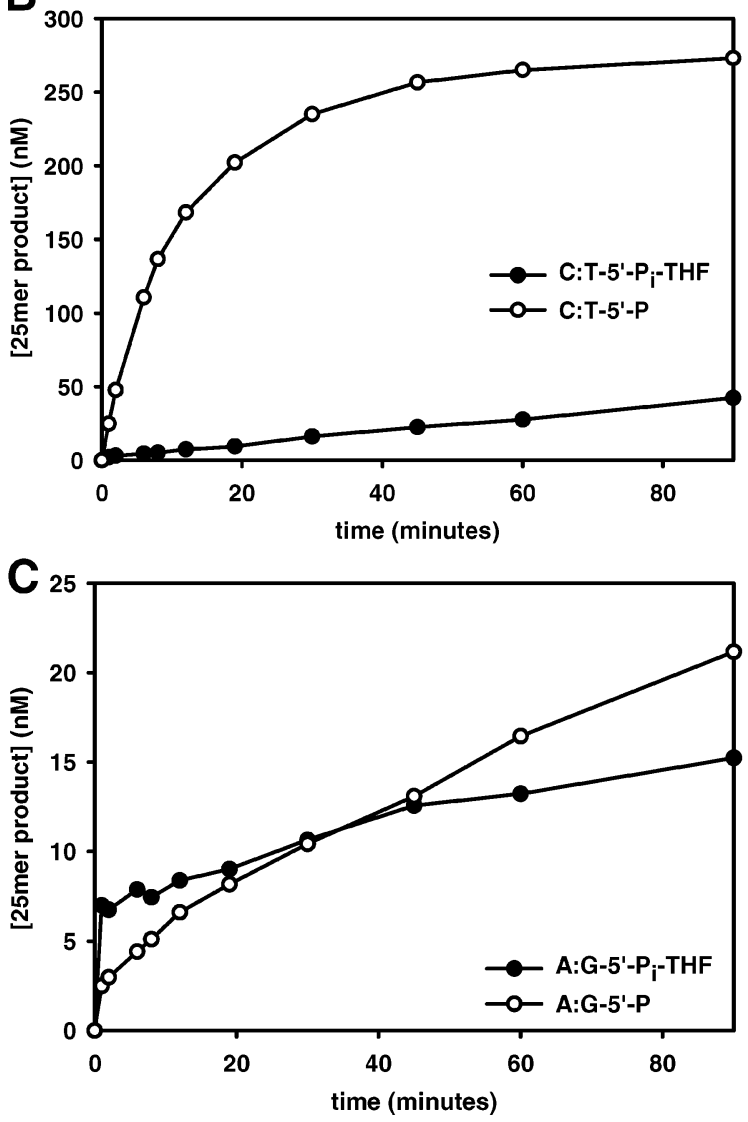

FIGURE 10: Influence of a $5^{\prime}$-dRP analogue on gap-filling by ASFV Pol $\mathrm{X}$ and on nick-editing by ASFV APE. (A) Influence of the $5^{\prime}$ moiety on single-nucleotide gap-filling by Pol X. Reactions consisting of $75 \mathrm{nM}$ Pol X, $200 \mathrm{nM}$ gapped G, $9 \mathrm{mM}$ dCTP, and $9.5 \mathrm{mM}$ (total) $\mathrm{Mg}^{2+}$ were monitored by rapid chemical quench. The $5^{\prime}$ moiety of the gapped substrate was either phosphate $(\mathrm{P})$ or the tetrahydrofuran $5^{\prime}$-dRP analogue $5^{\prime}-\mathrm{P}_{\mathrm{i}}$-THF. (B and C) Influence of the $5^{\prime}$ moiety on nick-editing by ASFV APE. ASFV APE (13 $\mathrm{nM}$ ) was incubated with $300 \mathrm{nM}$ nicked substrate containing either $5^{\prime}$-phosphate $(\mathrm{P})$ or $5^{\prime}-\mathrm{P}_{\mathrm{i}}$-THF. The identity of the $3^{\prime}$ base pair of the nick is described as $\mathrm{X}: \mathrm{Y}$, where $\mathrm{X}$ is the templating nucleotide and $\mathrm{Y}$ is the nucleotide that would have been incorporated by Pol $X$ during gap-filling. Notice the different scales for the $y$ axes. See Figure 1 for detailed substrate structures.

5'-dRP lyase/hydrolase activity among the ASFV DNA repair proteins is under way.

Implications for the Hypothesis of Mutagenic DNA Repair in ASFV. Our previous demonstration that Pol $\mathrm{X}$ is extremely error-prone during single-nucleotide gap-filling led us to hypothesize that it might function as a "mutase", contributing to the diversity known to exist among ASFV isolates by replacing a chemically damaged nucleotide with an undamaged, although incorrect, nucleotide $(30,31)$. Consistent with this hypothesis was our subsequent finding that the ASFV DNA ligase seals nicks containing 3' mismatched base pairs (the products of aberrant gap filling by Pol X) more efficiently than any DNA ligase characterized to date (34). Our present demonstration of a $3^{\prime} \rightarrow 5^{\prime}$ exonuclease activity for ASFV APE (Figure 8C) indicates that the frequency at which mismatched contiguous duplex products emerge from the ASFV DNA repair pathway, as well as the identity of those mismatches, will be a function of (i) the substrate specificities of all three proteins (Pol X, ASFV DNA ligase, and ASFV APE) and (ii) the relative concentrations of the $3^{\prime}$ mismatch sealer (DNA ligase) and the $3^{\prime}$ mismatch editor (APE). Note that ASFV does not encode a mismatch repair system or a mismatch-specific DNA glycosylase (23); therefore, once ligated into a contiguous duplex, a mismatch is expected to be refractory to further processing.

Whereas the $3^{\prime} \rightarrow 5^{\prime}$ exonuclease activity of ASFV APE processes the correctly matched $\mathrm{C}: \mathrm{G}$ and $\mathrm{A}: \mathrm{T}$ nicks with similarly poor efficiency (Figure 8C), mismatched C:T (the preferred substrate of ASFV DNA ligase) is edited 43-fold more efficiently than mismatched A:G (the least efficient substrate for ASFV DNA ligase). What determines the specificity of nick-editing by ASFV APE? How does the protein differentiate between matches and mismatches at the $3^{\prime}$ side of a nick? To what extent does ASFV APE enhance the fidelity of the ASFV DNA repair pathway? To begin answering these questions, a complete profile for ASFV APE $3^{\prime} \rightarrow 5^{\prime}$ exonuclease activity as a function of $3^{\prime}$ base pair identity is being pursued.

While initiation of AP site repair by an AP lyase gives repair intermediates possessing a $5^{\prime}$-phosphate moiety, initiation by an AP endonuclease gives intermediates with a $5^{\prime}$ dRP moiety (Figure 9). Our finding that gap-filling by Pol $\mathrm{X}$ is not hindered by a $5^{\prime}$-dRP analogue (Figure 10A) suggests that $5^{\prime}$-dRP-containing nicks may constitute significant intermediates in the ASFV DNA repair pathway; the extent to which these accumulate will depend upon the relative activities and concentrations of Pol X versus the $5^{\prime}$-dRP lyase/hydrolase (assuming that the latter exists in ASFV). Note that 5 -dRP-containing nicks are expected to be abundant intermediates in eukaryotic base excision repair because $5^{\prime}$-dRP removal is the rate-limiting step (56). Relative to 5'phosphate, $5^{\prime}$-dRP reduces the efficiency with which ASFV APE edits nicks (parts B and C of Figure 10); this is similar to what has been observed for both Ape1 and endonuclease IV (57). Although the influence of $5^{\prime}$-dRP on the fidelity of gap-filling by Pol X has not yet been examined, the present data suggest that the APE-initiated route of AP site repair will be more error-prone, perhaps dramatically so, than the AP lyase-initiated route (in which $5^{\prime}$-dRP is never present to "protect" mismatch nicks from being edited prior by ligation).

\section{ACKNOWLEDGMENT}

We thank L. K. Dixon for ASFV clones BASE and BASH and B. Weiss for E. coli strain BW528.

\section{REFERENCES}

1. Dogliotti, E., Fortini, P., and Pascucci, B. (1997) in Base Excision Repair of DNA Damage (Hickson, I. D., Ed.) pp 81-101, Landes Bioscience, Austin, TX. 
2. Loeb, L. A., and Preston, B. D. (1986) Mutagenesis by apurinic/ apyrimidinic sites, Annu. Rev. Genet. 20, 201-230.

3. Guillet, M., and Boiteux, S. (2002) Endogenous DNA abasic sites cause cell death in the absence of Apn1, Apn2 and Rad1/Rad10 in Saccharomyces cerevisiae, EMBO J. 21, 2833-2841.

4. Nilsen, H., and Lindahl, T. (2004) in Encyclopedia of Biological Chemistry (Lennarz, W. J., and Lane, M. D., Eds.) pp 603-608, Elsevier Ltd., Oxford, U.K.

5. Prasad, R., Beard, W. A., Strauss, P. R., and Wilson, S. H. (1998) Human DNA polymerase $\beta$ deoxyribose phosphate lyase, J. Biol. Chem. 273, 15263-15270.

6. McCullough, A. K., Dodson, M. L., and Lloyd, S. R. (1999) Initiation of base excision repair: Glycosylase mechanisms and structures, Аnnu. Rev. Biochem. 68, 255-285.

7. Levin, J. D., and Demple, B. (1990) Analysis of class II (hydrolytic) and class I ( $\beta$-lyase) apurinic/apyrimidinic endonucleases with a synthetic DNA substrate, Nucleic Acids Res. 18, 5069-5075.

8. Friedberg, E. C., Walker, G. C., and Siede, W. (1995) in DNA Repair and Mutagenesis, pp 167-168, American Society of Microbiology, Washington, DC.

9. Mol, C. D., Hosfield, D. J., and Tainer, J. A. (2000) Abasic site recognition by two apurinic/apyrimidinic endonuclease families in DNA base excision repair: The $3^{\prime}$ ends justify the means, Mutat. Res. 460, 211-229.

10. Mol, C. D., Kuo, C.-F., Thayer, M. M., Cunningham, R. P., and Tainer, J. A. (1995) Structure and function of the multifunctional DNA-repair enzyme exonuclease III, Nature 374, 381-386.

11. Hosfield, D. J., Guan, Y., Haas, B. J., Cunningham, R. P., and Tainer, J. A. (1999) Structure of the DNA repair enzyme endonuclease IV and its DNA complex: Double-nucleotide flipping at abasic sites and three-metal-ion catalysis, Cell 98, 397408.

12. Demple, B., Johnson, A., and Fung, D. (1986) Exonuclease III and endonuclease IV remove $3^{\prime}$ blocks from DNA synthesis primers in $\mathrm{H}_{2} \mathrm{O}_{2}$-damaged Escherichia coli, Proc. Natl. Acad. Sci. U.S.A. 83, 7731-7735.

13. Levin, J. D., Johnson, A. W., and Demple, B. (1988) Homogeneous Escherichia coli endonuclease IV: Characterization of an enzyme that recognizes oxidative damage in DNA, J. Biol. Chem. 263, 8066-8071.

14. Winters, T. A., Henner, W. D., Russell, P. S., McCullough, A., and Jorgensen, T. J. (1994) Removal of 3'-phosphoglycolate from DNA strand-break damage in an oligonucleotide substrate by recombinant human apurinic/apyrimidinic endonuclease 1, Nucleic Acids Res. 22, 1866-1873.

15. Henner, W. D., Grunberg, S. M., and Haseltine, W. A. (1983) Enzyme action at $3^{\prime}$ termini of ionizing radiation-induced DNA strand breaks, J. Biol. Chem. 258, 15198-15205.

16. Chou, K.-M., and Cheng, Y.-C. (2002) An exonucleolytic activity of human apurinic/apyrimidinic endonuclease on $3^{\prime}$ mispaired DNA, Nature 415, 655-659.

17. Ishchenko, A. A., Yang, X., Ramotar, D., and Saparbaev, M. (2005) The $3^{\prime} \rightarrow 5^{\prime}$ exonuclease of Apn1 provides an alternative pathway to repair 7,8-dihydro-8-oxodeoxyguanosine in Saccharomyces cerevisiae, Mol. Cell. Biol. 25, 6380-6390.

18. Ischenko, A. A., and Saparbaev, M. K. (2002) Alternative nucleotide incision repair pathway for oxidative DNA damage, Nature 415, 183-187.

19. Ishchenko, A. A., Sanz, G., Privezentzev, C. V., Maksimenko, A. V., and Saparbaev, M. (2003) Characterization of new substrate specificities of Escherichia coli and Saccharomyces cerevisiae AP endonucleases, Nucleic Acids Res. 31, 6344-6353.

20. Gros, L., Ishchenko, A. A., Ide, H., Elder, R. H., and Saparbaev, M. K. (2004) The major human AP endonuclease (Ape1) is involved in the nucleotide incision repair pathway, Nucleic Acids Res. 32, 73-81.

21. Ishchenko, A. A., Ide, H., Ramotar, D., Nevinsky, G., and Saparbaev, M. (2004) $\alpha$-Anomeric deoxynucleotides, anoxic products of ionizing radiation, are substrates for the endonuclease IV-type AP endonucleases, Biochemistry 43, 15210-15216.

22. Afonso, C. L., Tulman, E. R., Lu, Z., Oma, E., Kutish, G. F., and Rock, D. L. (1999) The genome of Melanoplus sanguinipes entomopoxvirus, J. Virol. 73, 533-552.

23. Yanez, R. J., Rodriguez, J. M., Nogal, M. L., Yuste, L., Enriquez, C., Rodriguez, J. F., and Vinuela, E. (1995) Analysis of the complete nucleotide sequence of African swine fever virus, Virology 208, 249-278.
24. Blasco, R., Aguero, M., Almendral, J. M., and Vinuela, E. (1989) Variable and constant regions in African swine fever virus DNA, Virology 168, 330-338.

25. Enjuanes, L., Cubero, I., and Vinuela, E. (1977) Sensitivity of macrophages from different species to African swine fever (ASF) virus, J. Gen. Virol. 34, 455-463.

26. Vinuela, E. (1985) African swine fever virus, Curr. Top. Microbiol. Immunol. 116, 151-171.

27. Brookes, S. M., Dixon, L. K., and Parkhouse, R. M. E. (1996) Assembly of African swine fever virus: Quantitative ultrastructural analysis in vitro and in vivo, Virology 224, 84-92.

28. Rojo, G., Garcia-Beato, R., Vinuela, E., Salas, M. L., and Salas, J. (1999) Replication of African swine fever virus DNA in infected cells, Virology 257, 524-536.

29. Oliveros, M., Yanez, R. J., Salas, M. L., Salas, J., Vinuela, E., and Blanco, L. (1997) Characterization of an African swine fever virus $20-\mathrm{kDa}$ DNA polymerase involved in DNA repair, J. Biol. Chem. 272, 30899-30910.

30. Showalter, A. K., and Tsai, M.-D. (2001) A DNA polymerase with specificity for five base pairs, J. Am. Chem. Soc. 123, 17761777.

31. Showalter, A. K., Byeon, I.-J. L., Su, M.-I., and Tsai, M.-D. (2001) Solution structure of a viral DNA polymerase $\mathrm{X}$ and evidence for a mutagenic function, Nat. Struct. Biol. 8, 942-946.

32. Hammond, J. M., Kerr, S. M., Smith, G. L., and Dixon, L. K. (1992) An African swine fever virus gene with homology to DNA ligases, Nucleic Acids Res. 20, 2667-2671.

33. Yanez, R. J., and Vinuela, E. (1993) African swine fever virus encodes a DNA ligase, Virology 193, 531-536.

34. Lamarche, B. J., Showalter, A. K., and Tsai, M.-D. (2005) An error-prone viral DNA ligase, Biochemistry 44, 8408-8417.

35. Dixon, L. K., Twigg, S. R. F., Baylis, S. A., Vydelingum, S., Bristow, C., Hammond, J. M., and Smith, G. L. (1994) Nucleotide sequence of a $55 \mathrm{kpp}$ region from the right end of the genome of a pathogenic African swine fever virus isolate (Malawi LIL20/ 1), J. Gen. Virol. 75, 1655-1684.

36. Dixon, L. K., and Wilkinson, P. J. (1988) Genetic diversity of African swine fever virus isolates from soft ticks (Ornithodoros moubata) inhabiting warthog burrows in Zambia, J. Gen. Virol. 69, 2981-2993.

37. Cunningham, R. P., Saporito, S. M., Spitzer, S. G., and Weiss, B. (1986) Endonuclease IV (nfo) mutant of Escherichia coli, J. Bacteriol. 168, 1120-1127.

38. Thompson, J. D., Higgins, D. G., and Gibson, T. J. (1994) CLUSTAL W: Improving the sensitivity of progressive multiple sequence alignment through sequence weighting, position-specific gap penalties and weight matrix choice, Nucleic Acids Res. 22, 4673-4680.

39. Mazumder, A., Gerlt, J. A., Absalon, M. J., Stubbe, J., Cunningham, R. P., Withka, J., and Bolton, P. H. (1991) Stereochemical studies of the $\beta$-elimination reactions at aldehydic abasic sites in DNA: Endonuclease III from Escherichia coli, sodium hydroxide, and Lys-Trp-Lys, Biochemistry 30, 1119-1126.

40. Garcia-Escudero, R., Garcia-Diaz, M., Salas, M. L., Blanco, L., and Salas, J. (2003) DNA polymerase X of African swine fever virus: Insertion fidelity on gapped DNA substrates and AP lyase activity support a role in base excision repair of viral DNA, $J$. Mol. Biol. 326, 1403-1412.

41. Lesiak, K. B., and Wheeler, W. H. (1990) Formation of $\alpha$-deoxyadenosine in polydeoxynucleotides exposed to ionizing radiation under anoxic conditions, Radiat. Res. 121, 328-337.

42. Bonicel, A., Mariaggi, N., Hughes, E., and Teoule, R. (1980) In vitro gamma irradiation of DNA: Identification of radioinduced chemical modifications of the adenine moiety, Radiat. Res. 83 , 19-26.

43. Levin, J. D., Shapiro, R., and Demple, B. (1991) Metalloenzymes in DNA repair: Escherichia coli endonuclease IV and Saccharomyces cerevisiae Apn1, J. Biol. Chem. 266, 22893-22898.

44. Beckman, R. A., Mildvan, A. S., and Loeb, L. A. (1985) On the fidelity of DNA replication: Manganese mutagenesis in vitro, Biochemistry 24, 5810-5817.

45. Sirover, M. A., and Loeb, L. A. (1977) On the fidelity of DNA replication. Effect of metal activators during synthesis with avian myeloblastosis virus DNA polymerase, J. Biol. Chem. 252, 36053610.

46. Wang, T. S., Eichler, D. C., and Korn, D. (1977) Effect of $\mathrm{Mn}^{2+}$ on the in vitro activity of human deoxyribonucleic acid polymerase $\beta$, Biochemistry 16, 4927-4934. 
47. Tong, J., Barany, F., and Cao, W. (2000) Ligation reaction specificities of an $\mathrm{NAD}^{+}$-dependent DNA ligase from the hyperthermophile Aquifex aeolicus, Nucleic Acids Res. 28, 1447-1454.

48. Shuman, S. (1995) Vaccinia virus DNA ligase: Specificity, fidelity, and inhibition, Biochemistry 34, 16138-16147.

49. Weymouth, L. A., and Loeb, L. A. (1978) Mutagenesis during in vitro DNA synthesis, Proc. Natl. Acad. Sci. U.S.A. 75, 19241928.

50. Tong, J., Cao, W., and Barany, F. (1999) Biochemical properties of a high fidelity DNA ligase from Thermus species AK16D, Nucleic Acids Res. 27, 788-794.

51. Vallee, B. L., and Galdes, A. (1984) The metallobiochemistry of zinc enzymes, Adv. Enzymol. Relat. Areas Mol. Biol. 56, 283430.

52. Donaire, A., Salgado, J., Jimenes, H. R., and Moratal, J. M. (1995) Cobalt-substituted proteins, NATO ASI Ser., Ser. C 457, 213244.

53. Ljungquist, S. (1977) A new endonuclease from Escherichia coli acting at apurinic sites in DNA, J. Biol. Chem. 252, 2808-2814.
54. Lindahl, T. (1993) Instability and decay of the primary structure of DNA, Nature 362, 709-715.

55. Price, A., and Lindahl, T. (1991) Enzymatic release of 5'-terminal deoxyribose phosphate residues from damaged DNA in human cells, Biochemistry 30, 8631-8637.

56. Srivastava, D. K., Berg, B. J. V., Prasad, R., Molina, J. T., Beard, W. A., Tomkinson, A. E., and Wilson, S. H. (1998) Mammalian abasic site base excision repair: Identification of the reaction sequence and rate-determining steps, J. Biol. Chem. 273, 2120321209.

57. Wong, D., DeMott, M. S., and Demple, B. (2003) Modulation of the $3^{\prime} \rightarrow 5^{\prime}$-exonuclease activity of human apurinic endonuclease (Ape1) by its $5^{\prime}$-incised abasic DNA product, J. Biol. Chem. 278, $36242-36249$.

58. Unk, I., Haracska, L., Johnson, R. E., Prakash, S., and Prakash, L. (2000) Apurinic endonuclease activity of yeast Apn2 protein, J. Biol. Chem. 275, 22427-22434.

BI051772G 